العدد الحادي والأربعون

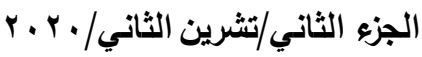

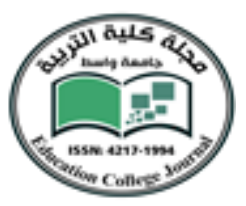

\title{
مشاكل المدن العربية وسبل معالجتها
}

أ.د. جمعة علي داي

جامعة كرميان/ كلية اللغات و العلوم الإنسانية - خاتقين

juma.ali@garmian.edu.krd

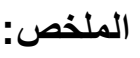

أن معظم المدن في العالم تتوسع وتزداد أحجامها بسبب زيادة السكان والهجرة من الأرياف إلى المدن للبحث عن فرص العمل لان مستوى الأجور اعلى من الأرياف وبشكل خاص في مدن الدول العربية، وأصبحت ظاهرة التحضر ظاهرة عالمية في جميع دول العالم بما فيها العالم الثالث المتضمن هن للدول العربية وهي ترتبط بعدة عوامل اقتصادية واجتماعية، ونلاحظ بان التحضر في الدول المنطورة بدأت بمراحل زمنية متعاقبة وبأسلوب مخطط لها دون القزز لمراحل سربعة على عكس الحالة في الدول العربية التي بدأت فيها ظاهرة التحضر بأسلوب سربع وغير مخطط وبصورة عشوائية أثرت على حجم مدن الدول العربية وسببت مشاكل عديدة من خلال زيادة قوافل الوافدين من الأرياف إلى المدن بحثاً عن ظروف حياة افضل من الأرياف، ولكن عملية التحضر السربعة في المدن العربية سببت ظهور مشاكل عديدة من الصعوبة السيطرة عليها بشكل شامل بل يمكن إيجاد حلول مرحلية تؤدي إلى التقليل من آثارها داخل المدن العربية وفي منت البحث بنيت مشاكل المدن العربية وسبل معالجتها، ومنها مشاكل السكن والنقل والضغط على المرافق العامة والخدات الرئيسية مثل توفير الماء والكهرباء وعمليات الصرف الصحي والمجاري والخدمات التعليمية والصحية والاجنماعية،

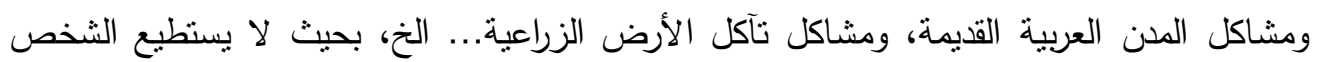
الوافد من القربة التأقلم بسرعة مع الواقع الجديد في المدينة إضافة إلى خلق مشاكل نفسية واجتماعية من خلال سكن عدة عوامل في البيت الواحد والحمامات تكون مشتركة وكذلك الحصول على المياه غيرها، وهذه المشاكل نتاولتها بالتقصيل في منت البحث مع بيان معالجة كل مشكلة. وتعاني المدينة العربية مشاكل أخرى منها نقص الخدمات الترفيهية والمناطق المفتوحة والمناطق الخضراء وإضافة إلى حدوث مشاكل اجتماعية منعددة.

وأن اكثر المدن العرية توسعت بصورة عشوائية وخاصةً في نهاية القرن العشرين بسبب الهجرة السريعة من الأرياف إلى المناطق الحضرية وهذا سبب نقص كبير في القوى العاملة الزراعية في 


$$
\begin{aligned}
& \text { العدد الحادي والأربعون }
\end{aligned}
$$

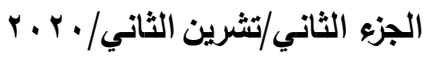

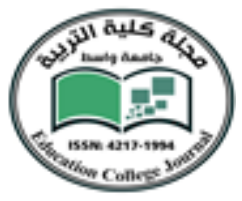

$$
\begin{aligned}
& \text { المدن بسبب زيادة أعداد سكان الددن العربية مما أثرت على التركيب الداخلي للمدن العربية. } \\
& \text { الكلمات المفتاحية: المدن العربية، مشاكلها، وسبل معالجتها }
\end{aligned}
$$

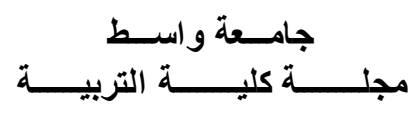

(The problems of Arab Cities and the ways of treatment)

\section{Research Summary}

Most cities in the world enlarge and grow big in size due to the decrease of population and immigration from countryside to cities looking for work opportunities because the level wages are higher in cities rather in the countryside specially in Arab country cities. The civilized phenomenon becomes global phenomenon in all world countries including the third world country which Arab countries belong to and it is related with many facters economic and social.

We can notice that civilized or civilization in developed countries began with sequence period stages with planned way without quick jumping, on the contrary in Arab countries which the civilized phenomenon began with quick way, unplanned and randomly and this affected the size of Arab countries cities and made many problems which make increasing number of those who come from countryside to cities looking for the best life chances ,but this create many problems that it was difficult to control,but it could find stage solutions lead to lessen their effect inside Arab countries and in the research the problems of Arab Cities have been shown and also the ways of treatments.Among those problems accommodation, transportation ,press on general facilities, general services like water, electricity and sewage, education, health and social care services and problems of old cities,also the problems of agriculture land erosion......etc. since the citizen who came from countryside can't acclimatise quickly withdrawn the new state in the city.In addition to that psychological, social problems have been created through sharing many families one house, bathes and difficultly of getting water.All these problems have been shown minutely in the research with the treatment for each problem.

The Arab Cities suffer from other problems such as entertaining service shortages, open areas, and green zones ,besides many social problems.

Many cities enlarged in random way, especially at the end of twentieth century because of fast immigration from countryside to civilized zones and this caused a big shortage of agricultural work force in countryside which is considered the main source of providing the population the food they need.

The press on general services in cities due to increase of population in Arab Cities affected the inner stracture of Arab Cities. 
العدد الحادي والأربعون

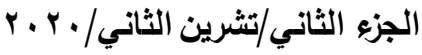

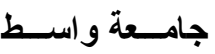

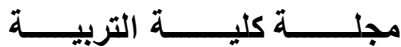

Introduction المقدمة

أصبحت الددن تعاني مناعب ومشكلات عديدة وخاصةً في مدن الدول العربية بسبب

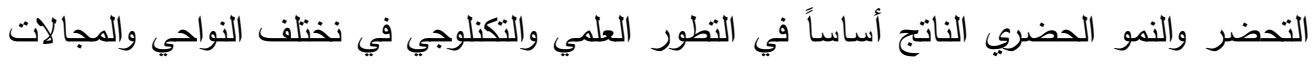
وما راققها من طرق البناء الحديثة وخاصة في مجال السكن والإسكان السكاني فثهدنا إنجازات قياسية بفضل البناءات الجاهزة والصناعية فظهرت الددن الحديثة التي تستقطب الملايين من السكان. وما من مدينة في العالم إلا وتعرضت لمشكلات حضرية عديدة انعكست سلبا على مجتمعا الحضري. ولقد جاء الاهتمام بدراسة الددن والذب يعتبر فرع مهم من فروع الجغرافية البشرية بسبب أهميته

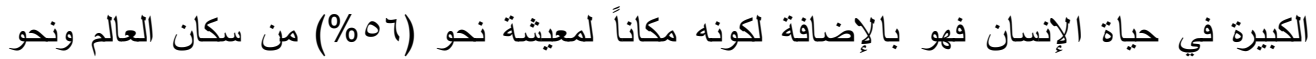
(r^\%) من سكان الدول المتقدمة فان المدينية تثكل المركز الرئيسي لأنشطتهم الاقتصادية والسياسية والاجتماعية ويمكن القول بان هي مصانع للحضارة الإنسانية. فبيئة الددن تعتبر من اكثر البيئات الجغرافية تغيراً على الإطلاق وتشكل نموذجاً رائعاً لما أحدثه الإنسان في بيئته الجغرافية من حيث بناء الدور السكنية وطرق النقل والمواصلات وبناء المصانع والحدائق والباركات والحسور والدحطات والأنفاق وبناء دور العلم والجامعات والمناطق الخضراء والمناطق المفتوحة. وعليه فان الددينية هي البيئة الني صنعها الإنسان بنفسه لنفسه.

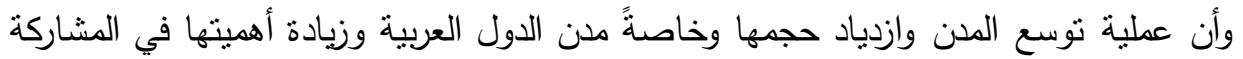
في تطور الظاهرة الحضرية في العالم مما جلب اهتمام أصحاب الاختصاص من الباحثين في مجال الجغرافية وتخطيط المدن كل من اختصاصه وحسب كل زاويا الددينة التي تتعلق باختصاصه الدقيق. ومعظم الددن في الدول العربية نوسعة بشكل كبير عشوائي وخاصة في نهاية القرن العشرين

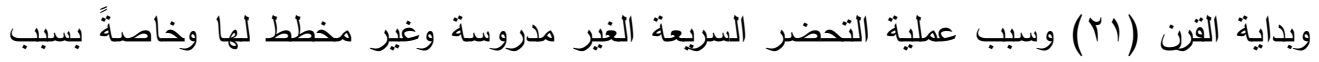
الهجرة السريعة من الأرياف إلى المدن مما سبب مشاكل كثيرة في المناطق الريفية المهاجرين منها وخلق نقص الأيدي العاملة الزراعية وسببت الضغط المتزايد على معظم الخدمات الأساسية في معظم

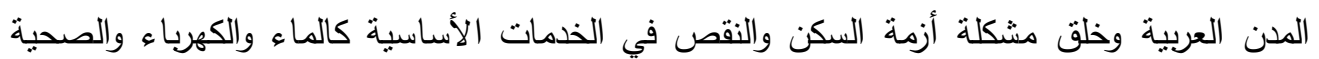
والتعليمية... الخ وانتشار الفوضى إضافة إلى مشاكل اجتماعية كبيرة، يضاف إلى ذلك حالة عدم الانسجام مع الوضع الجديد في الددينة لان معظم السكان المهاجرين من القرى إلى المدن يتميزون

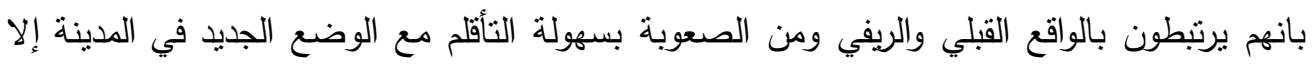
بعد فترة طويلة من الزمن وبذلك نلاحظ حدوث المشاكل الكثيرة في المدينة خاصة المشاكل 
العدد الحادي والأربعون

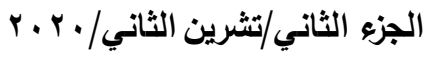

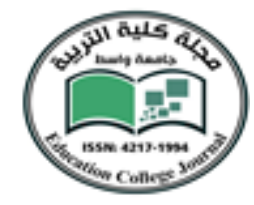

الاجتماعية والاقتصادية ونقص الخدمات الأساسية في معظم الددن العربية وهذا ما سنوضحه في

مشكلات المدن العربية Problems in Arabic Cities

التمهيد:

تعتبر عملية التحضر ظاهرة عالمية في الدول المنظورة والنامية وهي مرتبطة بعدة عوامل اقتصادية واجتماعية تتمنل داخل الدولة بتزايد سكان المدن ونمو المدن الكبرى ونشوء المجمعات المدينية العملاقة التي تضم عدة مدن مع ضواحيها.

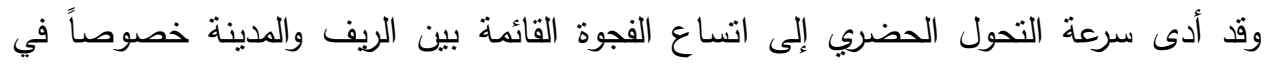

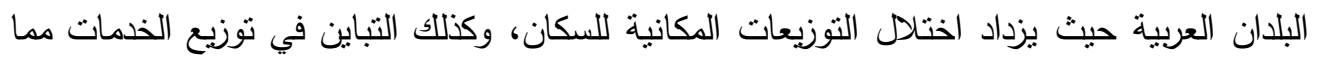
يسبب انتقال الأفراد من المناطق الريفية إلى المدن نتيجة حرمان الأرياف من الخمات الأساسية

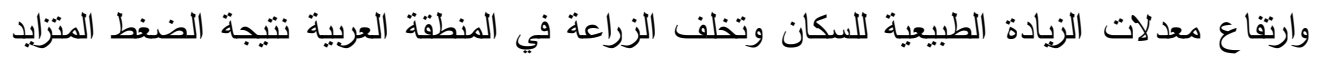
على الموارد الزراعية المحدودة وانخفاض الإنتاجية.

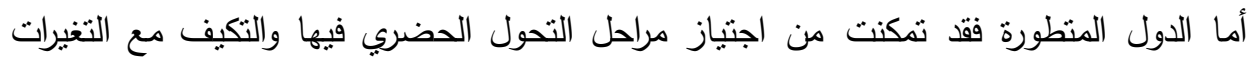

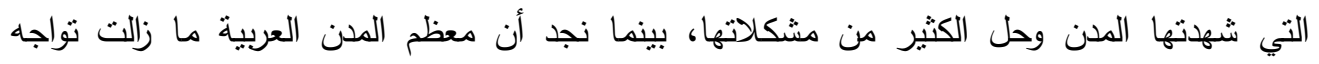

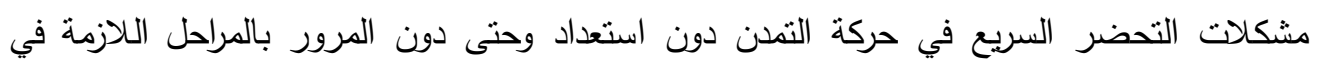
سلسلة النحولات الحضرية وهناك خصائص مشتركة في التجمعات الحضرية في مدن المنطقة العربية

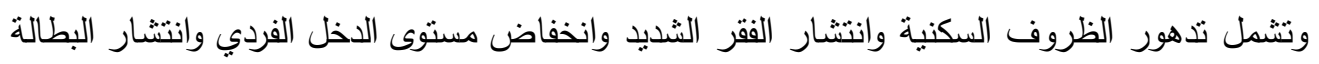
أما تزايد موجات الوافدين للعمل في المدينة، وانتشار ظاهرة السكن العشوائي والتي تفتقر إلى الخدمات

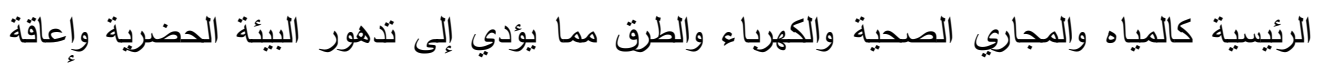
مخططات التتمية الاجتماعية والاقتصادية. أن المشكلة الرئيسية في حركة التمدين، ترجع إلى عدم التوافق بين زيادة السكان في المدن

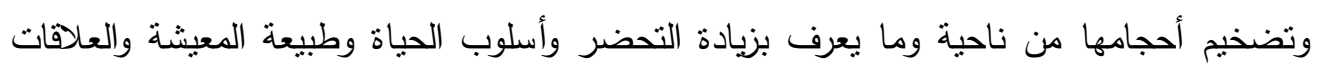

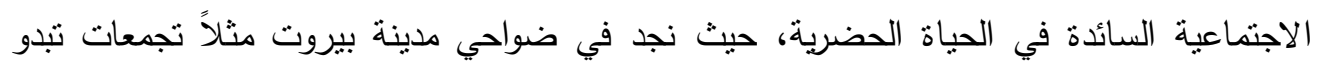

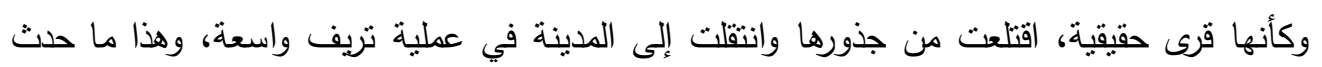

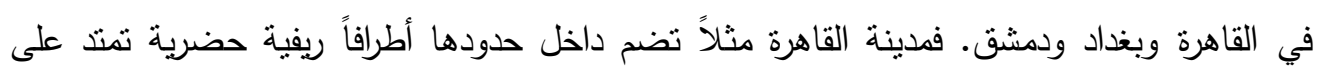

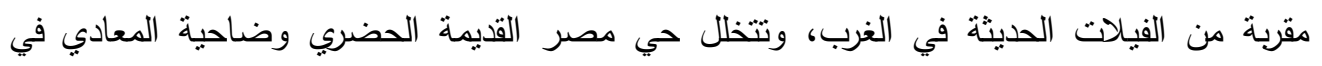
الجنوب في شكل بيوت ذات طابق واحد من الطين. ويمكن الإثارة أيضاً إلى أن حي الثرابية الذي في 
العدد الحادي والأربعون

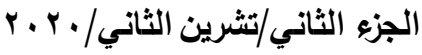

يقع في منطقة الاستقرار الشمالية يمنل في القاهرة منطقة ريفية بحتة سنحاول في هذا البحث عرض بعض المشاكل الحضرية التي تواجهها المدن العربية ونسلط الضوء على ارتباط هذه المشاكل بالعوامل والمحددات الرئيسية في عملية النمو الحضري وذلك للاستفادة منها في وضع سياسة عامة للتخطيط الحضري.

\section{Housing Problem in the City - مشكنة السكن في المدينة}

يعتبر السكن من الحاجات الضرورية للإنسان والتي لا يسنطيع العيش بدونها. فهو يعادل في أهية الماء والغذاء والكساء' الدواء، حتى يعيش الإنسان عيشة عصرية تتماشى مع منطلبات حياته اليومية مخيما يقل المعروض من المساكن في السوق، يرتفع السعر للوحدة السكنية إلى الحدود الذي يعجز فيه الإنسان من فئات المجتمع المختلفة في الحصول على وحدة سكنية تؤويه وأسرته. أن معظم المدن العربية نعاني من مشكلة نقص في عدد المساكن المناسبة وخاصة بإضافة المهاجرين الجدد إلى المدينة.

ومشكلة الإسكان في المدينة العربية تأخذ صوراً عديدة فهي أما مشكلة عددية كعلاقة بين ما هو معروض من الوحدات السكنية وما هو مطلوب منها والذي يحدده سوق الإسكان أو مشكلة في توزيع الإسكان ووحداته أو مشكلة عدم توفر مساحات لإقامة مشاريع الإسكان عليها ... الخ. وربما يكون للمشكلة وجه أخر ففي مدينة العين بالإمارات فان نسبة المعروض من الوحدات السكنية اكثر من نسبة المطلوب. في حين وجد في مدينة القاهرة طبقا لإحصاء عام 19 ا9 عجز في الإسكان قدره الف وحدة سكنية وبلغت درجة التزاحم في الغرفة الواحدة (Y,V. ( ) المتوسط يصل إلى (r) أشخاص في الغرفة الواحدة. أما الوجه الأسوأ هو ما انحدر إليه مستوى الإسكان في بعض المدن سواء من حيث تخطيط المناطق السكنية والمساحة اللازمة لكل أصرة ويصيب الفرد من معدلات التزاحم والكثافات السكانية غير المحتملة ويقدر بعض الباحثين أن نسبة تتراوح بين (•r و •0 \% من سكان العواصم العربية يعيشون في مناطق سكنية فقيرة أو مساكن غير ملائمة ولنأخذ بيروت مثلاً على ذلك وحسب الإحصاءات الرسمية هناك (•r\%) من مجموع سكان العاصمة يمكن أن تصنف على أنها مناطق فقيرة وتستوعب هذه المساكن (• \&\%) من السكان في العاصمة وليس الوضع بأحسن حالاً في القاهرة حيث أن عدد المناطق الفقيرة تستوعب (0؛ من مجموع سكانها ومع ذلك ونجد أن هذه المشكلة اصبح لها ظواهر مؤشرات تلفت النظر ومن بين هذه المؤشرات التي تشير إلى وجود هذه المشكلة وتضخمها هي: 
العدد الحادي والأربعون

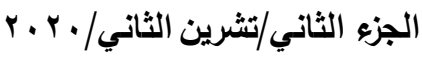

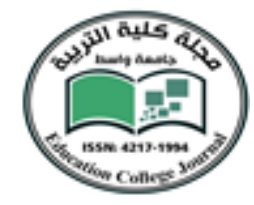

1 - وضوح ظاهرة غياب المسكن الملائم وارتفاع قيمة أو بدل إيجاره الثهري.

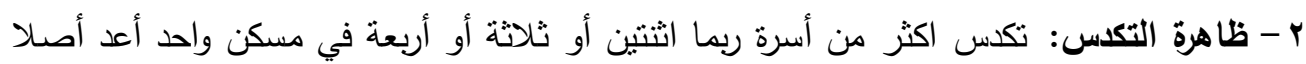
لسكن أسرة واحدة. r- ظاهرة التزاحم: أي تزاحم الأفراد في الغرفة الواحدة ثم باستمرار زحف سكان الأرياف إلى لى

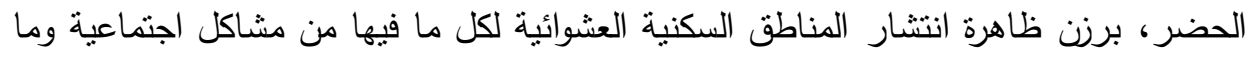
فيها من إهدار لمستوى البيئة بالخطر. وقد نتج عن ذللك ارتفاع الكثافات العمرانية وبارتفاعها تعددت المشاكل العمرانية ومنها:1 - مشكلة الصرف الصحي.

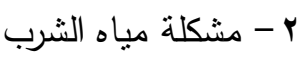

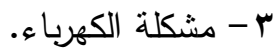
ع - مشكلة القصور في المرافق التعليمية. هـ - مشكلة القصور في مرافق الصحة العامة. צ - مشكلة النقل والمواصلات. وتبرز ارتفاع الكثافة السكانية في المدينة العربية كنتيجة مباشرة بين النمو العمراني والنمو

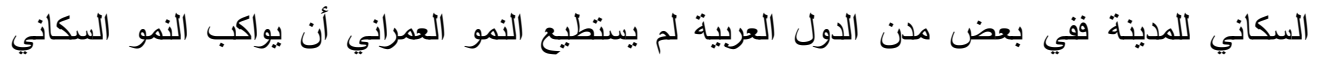

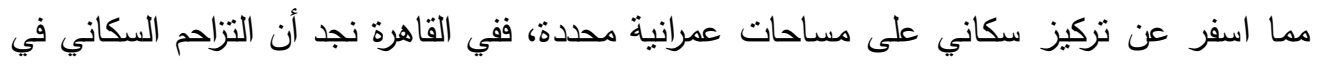
الثقق يصل إلى نسب عالية وخاصة في الأقسام الثنعبية من المدينة.

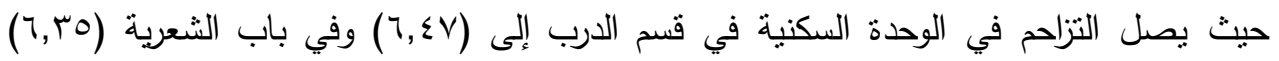

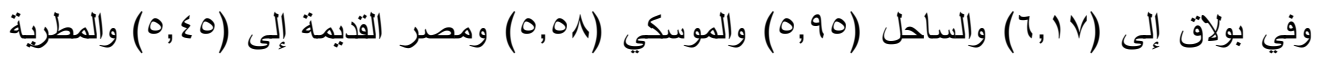

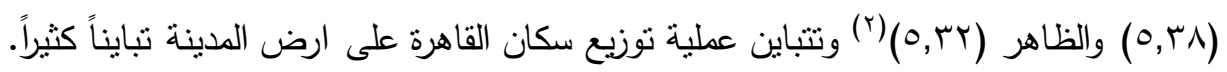

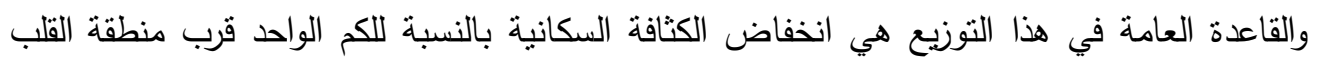

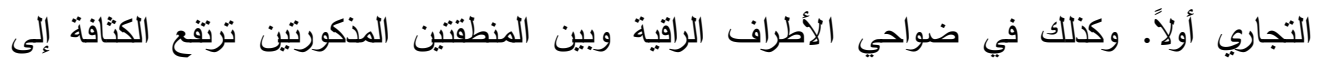
أقصاها وخاصة في الأحياء السكنية الثعبية الفقيرة وتتذفق إلى هذه المناطق هجرة الفقراء النازين الفين

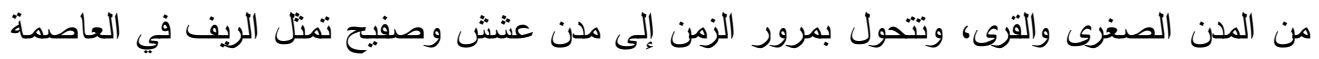

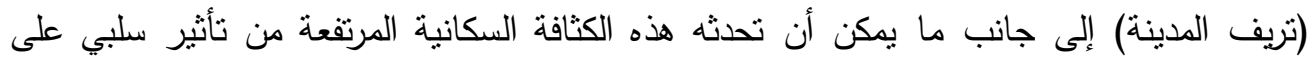

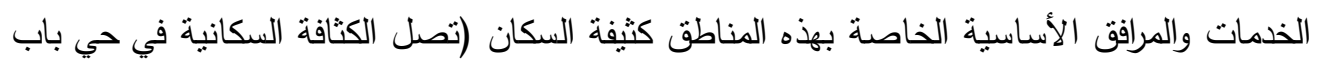

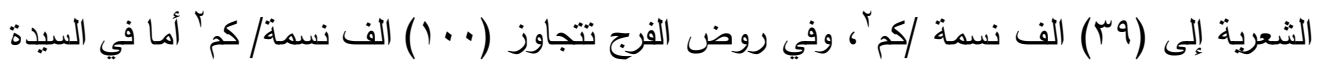


العدد الحادي والأربعون

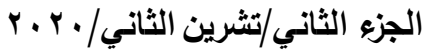

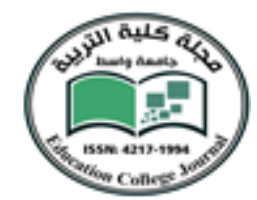

زينب فتبلغ (VY) الف نسمة/كم ملا شك أن الزيادة السكانية المطردة في المدن الكبرى في حصد كان لها انعكاس كبير على مشكلة الإسكان وتفاقمها بما يتزتب على هذه الزبادة في تكوين اسر جديدة بحاجة إلى مساكن جديدة ويؤدي نلك إلى ازدحام سكاني في كثير من أحياء القاهرة ويؤدي إلى انخفاض نصيب الفرد من المساحة المخصصة للاستعمال السكني. وأن خمسة الأف شخص في القاهرة يقيمون في كل كم واحد. وأن كل منر مربع في العاصمة يقيم عليه (0) أفراد. وتعتبر محافظة القاهرة من اكثر محافظات مصر طلبا للسكن ثم يليها محافظة الجيزة، وأن نسبة كبيرة من مباني مدينة القاهرة منداعية ومتهالكة وآيلة للسقوط و ( • \%\%) لا تصلح للسكن الآدمي، وأن ب/ من مباني القاهرة لا تصل إليها المياه ولا المجاري أو الكهرباء وأن نسبة ونية r: بعيشون في حجرة واحدة في المتوسط. وفي العراق تبلغ الكثافة السكانية (بr) شخص/كمَّ واحد. وتوجد اعلى كثافة في محافظة

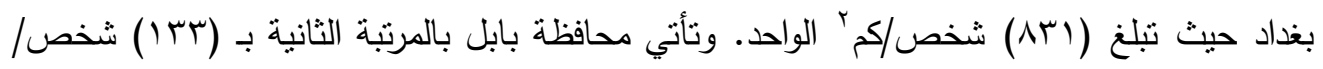

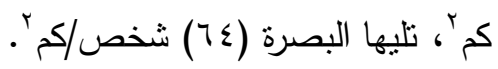
أما ادنى الكثافات السكانية فتوجد في المناطق الصحراوية. إذ تبلغ الكثافة السكانية في محافظة الأنبار أربعة أشخاص في الكمّ، تليها المثى بخمسة أشخاص لكل كم واحد. وأن الاختلافات في الكثافة السكانية في العراق ظهرت بسبب بروز دور المدن الطاغية وخصوصاً مدينة بغداد واختلال الثبكة الاجتماعية والاقتصادية في هذه المستوطنات وكذللك استمرار الهجرة من مناطق محددة (لمحافظات ميسان وذي قار) إلى بغداد والبصرة مما يسبب في عدم توازنها في التوزيع السكاني في العراق. وتعاني العائلة العراقية من مشكلة ارتفاع الإيجارات للدور السكنية. وارتفاع تكاليف شراء الأراضي السكنية وبناء دور سكن عليها بسبب ارتفاع قيمة مواد البناء وأجور العمل. ولقد ثبت وجود فرق شاسع بين معدل النمو للسكان في العراق وبين معدل نمو عدد الوحدات السكنية. ووفقا للإحصاءات الوطنية والدولية فان حاجة العراق إلى السكن الملائم تتراوح بين (r - م, ب) مليون وحدة سكنية بموجب إحصاءات الجهاز المركزي للإحصاء فان القطاع العام المسؤول الأول عن تشييد الوحدات السكنية للمواطنين لم يسنطع توفير هذه الوحدات خلال (·r) سنة الماضية ويعزي السبب إلى الحصار الاقتصادي الذي فرض على العراق لمدة (ب ا ) سنة وما تبعه من أحداث التخريب والسلب والنهب وانتقار الأمن بعد سقوط النظام السابق عام (r . . r) مما أدى إلى نوقف تشيبيد الوحدات السكنية حتى في القطاع الخاص ماعدا استثناءات بسيطة. أما بالنسبة إلى القطاع الخاص ووفقاً لاحصاءيات الجهاز المركزي للإحصاء فقد قام بإنشاء وحدات سكنية (دور سكن) بلغ 
العدد الحادي والأربعون

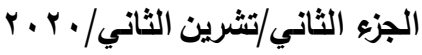

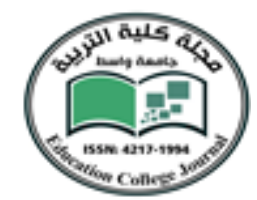

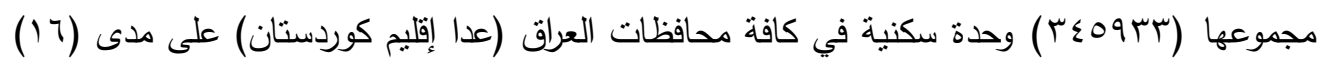

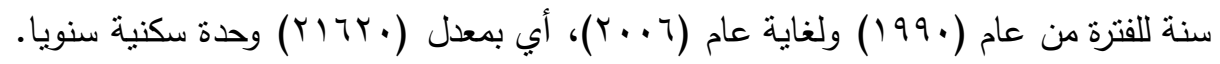
وأن مجموع التخصيصات المالية التي تم تخصيصها إلى وزارة الإسكان والتعمير خلال

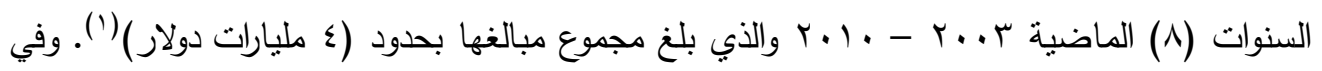

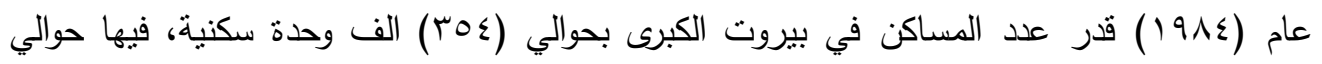

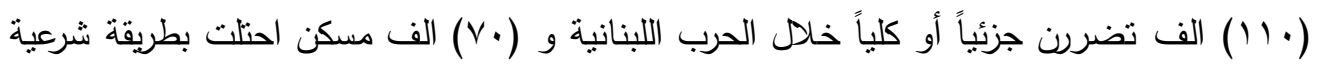

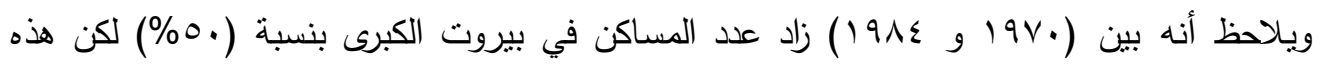
الزيادة اقتصرت على بناء المساكن الفخمة المعروضة للبيع والتي يفوق المعروض منها للطلب، بينما تزداد الحاجة إلى المساكن الشعبية لذوي الاخل المتوسط والمحدود. وقد عرفت مدينة ليبيا أزمة انتشار الأكواخ وأحياء الصفيح والسكن العشوائي خلال الخمسينات والستينات وخاصةً في مدينتي طرابلس وبنغازي وتحولت الضواحي إلى مدن الصفيح تكونت في أماكن عبارة عن مستقعات ومنخفضات معرضة للفيضانات الوديان كما حصل جنوب مدينة طرابلس وقد تكونت عدة أحياء في طرابلس كما في باب غشروخي سيدي المصري وحي سيدي خليفة وفي طريق المطار . ملئ ولكن من خلال تطبيق السياسات التي طبقت في مجال الإسكان تمكنت دولة ليبيا من القضاء على وفري مدن الصفيح والأكواخ وبذلك بحرق آخر كوخ خلال عام (9VVV) وأصبحت تضم مجموعة من الوحدات السكنية التي نشاهد عند مدخل مدينة طرابلس في اتجاه مطار طرابلس الدولي.

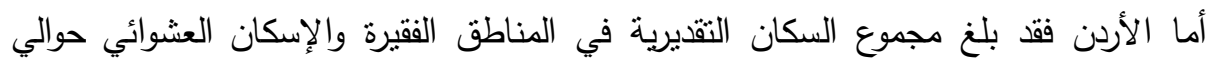
(V) (10. (10) الف نسمة ومعظم الساكنين هم اسر حديثة التكوين التي تركت المحميات وكان بمعدل أفراد في الوحدة السكنية كما أن اكثز تلك المساكن مكونة من غرفة واحدة، بحيث يبلغ منوسط الأفراد في الغرفة الواحدة (r,r). وتبرز المشكلات السكنية في مناطق مختلفة من المدن العربية بأثكال متتوعة نشمل أماكن السكن العشوائي وتضم الأحياء التي شينت في غياب القوانين والتشربعات ودون المستوى المطلوب بحيث يستحيل توفر الخدمات الاجتماعية لعدم وجود فراغات مناسبة لبناء مدرسة أو ملعب أو مستوصف أما حياة سكان المقابر تتميز بوجود نشاطات متعددة يمارسها السكان كذلك تتشر الأعمال اليومية منل نقل المياه ونتظيف الأحواض، ذلك أن غالبية السكان يعملون في مسكنهم بينما تشير تدفق طوفان الوافدين للإقامة الدائمة. 
العدد الحادي والأربعون

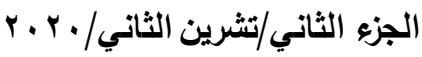

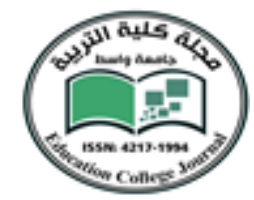

في بيروت (مثال ذلك) أحياء صفية أو حي السلم والمعمورة وبئر حسن. أما في المغرب

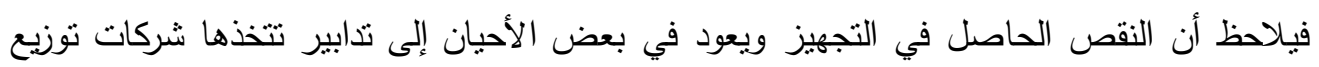

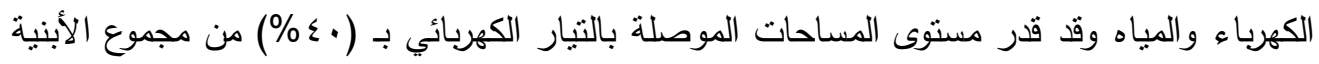
العشوائية وعدم وجود طرق رئيسية وطبق الأزمة، صعوبة دخول الزيارات إلى هذه الأحياء وانعدام

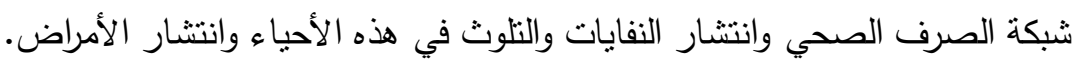

يمكن تحليد أسباب مشكلة السكن في مدن بعض الدول العربية بما يلي: The housing Problem in cities of Some Arab Countries can be identified as follows:

1 - تهام العديد من دور السكن في ظل أزمة تعيشها تلك الدول وتأخر أعمال التعمير وإعادة البناء

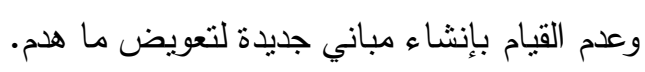
r - توقف الدولة عن القيام بالمشاريع الإسكانية وعن توزيع الأراضي على السكان أونى على هلى جمعيات بناء المساكن. أو ضعف برامج الإسكان. r - استئجار الدولة والثركات العديد من دور السكن المخصصة للسكان واستخدامها لأغراض أخرى غير سكنية كدوائر ومكاتب وغيرها. ـ - البطء الثديد في إنجاز مشاريع الإسكان من جراء نعقيدات حركة تكنلوجيا البناء ومواد البناء...

r - مشكلة المحافظة على المدينة العربية القليمة. Preserving Problem of the old Arabic city

أن التضخم الحضري والسكاني في الددينة العربية المعاصرة أدى إلى نركيز السكان في

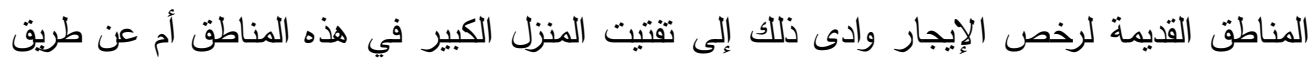
الورثة للرغبة في الاستقلال أو للاستفادة منه في إنشاء عمارات سكنية أو مكاتب أو محلات تلجارية.

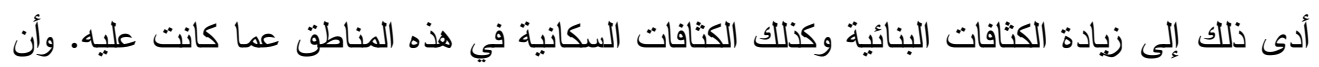
ذللك قد اثر على جميع المناطق القديمة والأثرية والتاريخية.

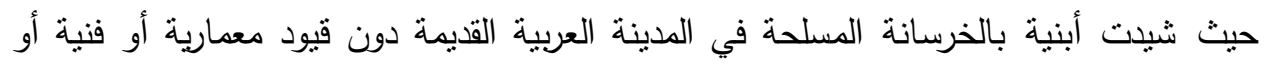

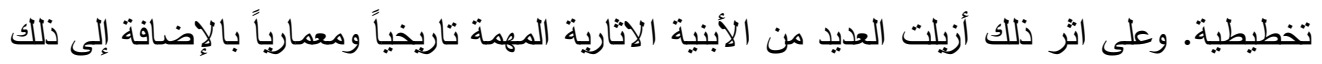

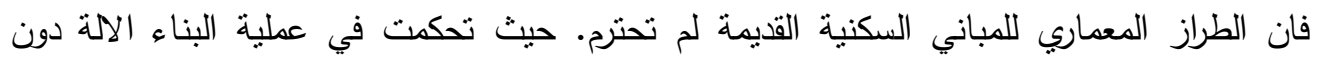
الإنسان والبيئة التي يحيا فيها. 
العدد الحادي والأربعون

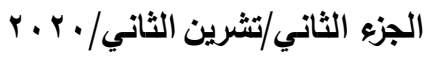

وبذلك انعدم الترابط بين المكونات المساحية للمدينة ومقوماتها المعنوية. ويلاحظ في عمليات التحديث وتجديد المدينة العربية القديمة الاختفاء التدريجي للطرز المعمارية العربية ويحل محلها طرز معمارية غربية أخرى كما تتألف الامتدادات العمرانية الحديثة من أبنية ذات طرز معمارية مستوردة، وبذلك تختفي الطرز المعمارية العربية في المناطق القديمة والحديثة على حد السواء وذللك لعدم انسجامها مع التراث الهندسي والمعماري والاجتماعي والثقافي وأخيراً تذهور البيئة ونأثير ذلك على نوعية ومستوى حياة أهل المدينة.

والمحاولات السربعة التي اتخذتها الدول العربية للمحافظة على هذا التراث، أخذت صورة ما يعرف بعمارة الواجهات مع أن المطلوب هو اختلاف المدارس العمرانية المختلفة ما بين الحديث والقديم وما بين الطراز العربي الإسلاهي والطراز الأوربي أدى نلك إلى فقدان المدن والعواصم العربية لشخصيتها المتميزة، حيث يشكل التخطيط الجديد والعمارة الحالية والنتائج المترتبة على ذلك للمشكلة الرئيسية

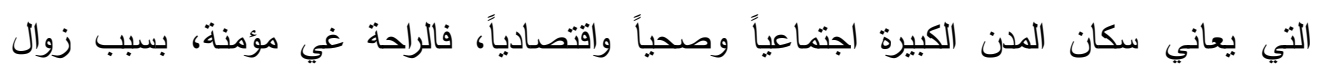
الخصوصية في هذه العمائر، كما أن شروط العزل الحراري والتهوية والتشميس لم تعد من القضايا التي يهتم بها المخطط الحضري والمهندس المعماري عند القيام بوضع التصاميم الأساسية للمدينة العربية وتصميم العمارة.

أن ما ربحناه من التقليد كان ضياع الهوية في كثثر من الأحيان حيث نم بعثرة المدينة العربية القديمة بفتح شوارع عريضة فيها وإزالة عناصر أساسية وهامة مناعت راية التحديث. وهكذا فقد العديد من هذه المدن هويتها نتيجةً بتز أجزاء هامة منها كما هو الحال بالنسبة لمدينة بغداد ودمشق وإنق والجزائر والقاهرة وغيرها حيث غرس فيها بشكل مصطنع عناصر جديدة ذات كتل غربية في مواقع هوه أحيائها القديمة وأن عملية الاكنظاظ أدى إلى عدم تحقيق الرؤية البصرية الجديدة للأبنية التاريخية والهامة وذلك لعدم وجود فراغات ومساحات كافية حولها. ومع تزايد عدد السكان وتوسع المدن العربية ثم هدم معظم المباني القديمة من وسط المدن وذللك لشق طرق النقل الواسعة كما حدث في معظم المدن الخليجية النفطية واستعانت بشركات عالمية لوضع مخططات مدنها وفق الأسس والتصاميم الغربية، منل الكويت، الرياض، وأبو ظبي ودبي والدوحة والعين والثـارقة. وقد أسفرت هذه التعديلات عن خارطة الطابع المعماري التراثي الذي يحمل تاريخ المدن العربية. 
العدد الحادي والأربعون

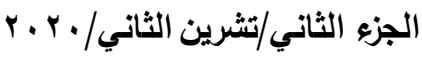

أن التركيب الداخلي للمدن العربية اليوم ينم بظاهرة تذهور المدينة القديمة وتوسع المدينة الحديثة

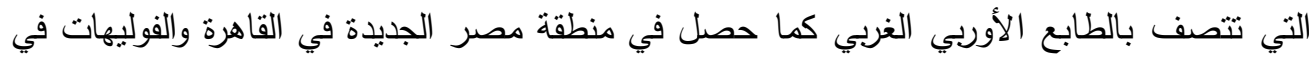

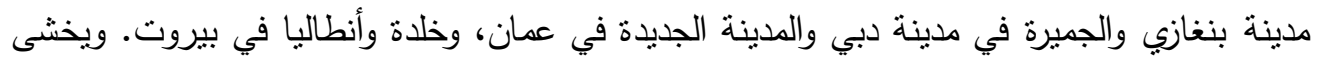

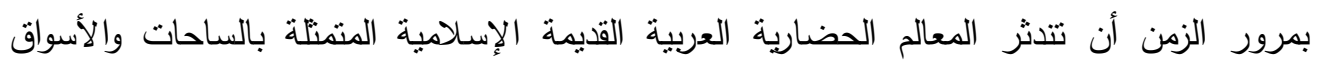

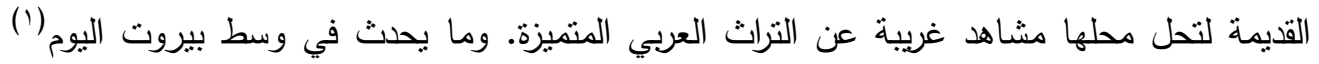
يعتبر نموذجاً لتغير معالم الددينة القديمة التي دمرتها الحرب ويلاحظ أن معظم المخططات الحديثة

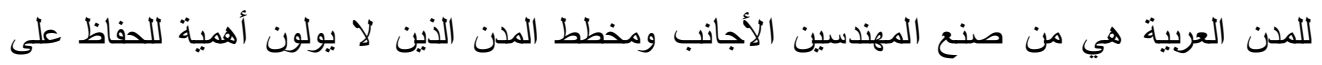
الماضي.

r ب- بيئة المدينة ومشاكل التلوث Environment city and Pollution Problem تلوث البيئة يعني التغير الحاصل في عامل أو اكثر من عوامل البيئة إذ هو تغير في خواص

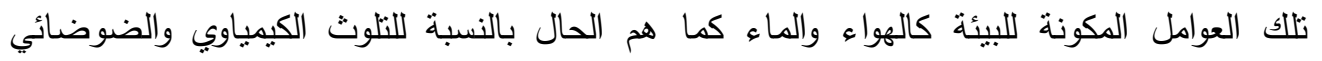

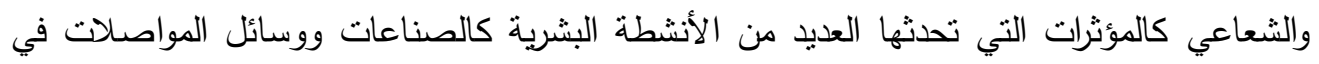

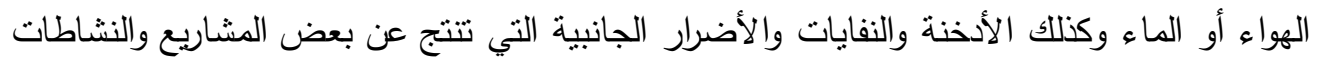
الاقتصادية كالسدود وحفر القنوات واقتنلاع الغابات وكنلك عن العوامل الطبيعية منل التلوث الفيزيائي والبايولوجي وأن اللتلوث اثأر سيئة على صحة الإنسان في المدينة وعلى مقدار وإنتاجيته في العمل.

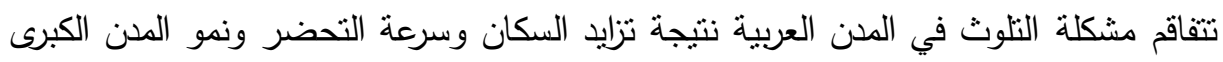

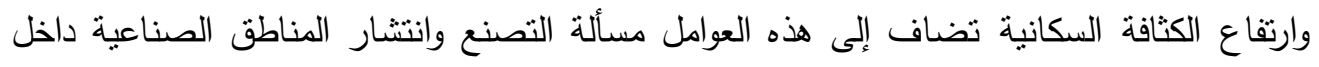

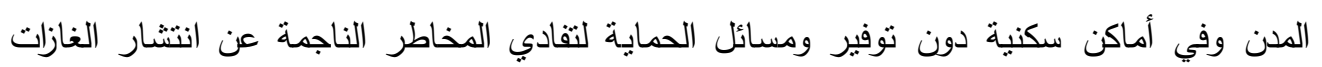

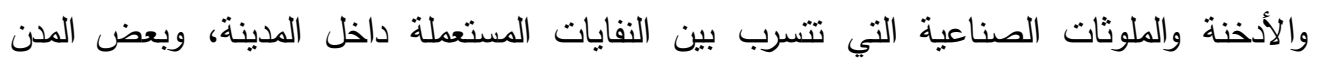

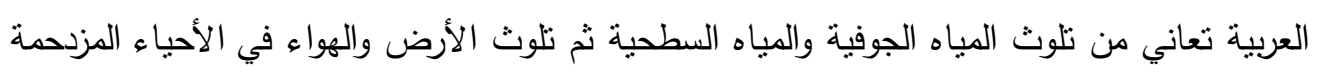
بالسكان.

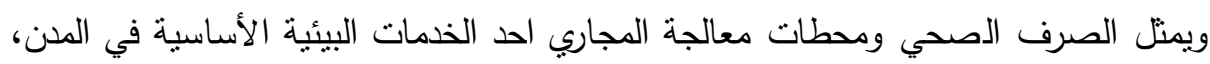
ولكن زيادة السكان في المدن العربية أدى إلى الضغط على خدمات شبكات الجة الصات الصرف الصحي وانتشار

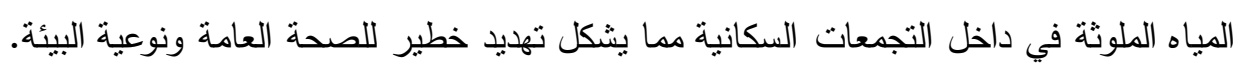

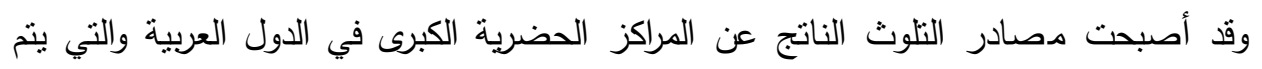
التخلص منها في المياه الإقليمية متل البحر الأبيض المنوسط والبحر الأحمر والخليج العربي هدنا لخطط عمل لحماية البيئة البحرية وفي حديقة عمان يوحد تلوث صناعي شديد في نهر الزرقاء تثميز 
العدد الحادي والأربعون

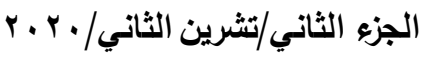

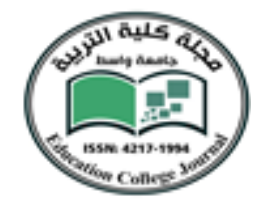

مياهها بان رائحتها كريهة ورديئة وغير صالحة للاستخدام البشري وذلك من خلال المجاري المعالجة الخارجة من محطة عين غزال وتمثل دليلاً واضحاً على رداءة الأداء في عملية المعالجة. وأن معظم الصناعات القائمة في منطقة عمان الكبرى تستخدم المياه بكميات كبيرة باستثناء صذاعة الخميرة، صناعات الفوسفات والورق ودبغ الجلود والبير ، وهناك معاناة من قبل المدن العربية في إدارة عمليات جمع النفايات والتخلص منها وهذه نسبب مشاكل تلوث كثيرة في المدن والأساليب

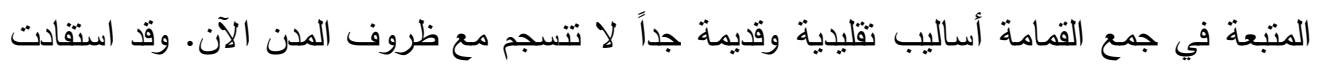
مصر في مجال تدبير الفضلات الصلبة التي ثبرز كمشكلة أساسية في القاهرة وحصلت هيأة نظافة وتجميل القاهرة على دعم لتطوير مشروعات الطمر الصحي في التربة الصحراوية الرملية وتحويل النفايات إلى سماد ونقل القمامة والاستفادة منها. ويختلف حجم المشكلات البيئية في المدن العربية بين بلد وآخر ففي حين توجد برامج شاملة ومعالجة في بعض الدول المصدرة للبترول لا توجد

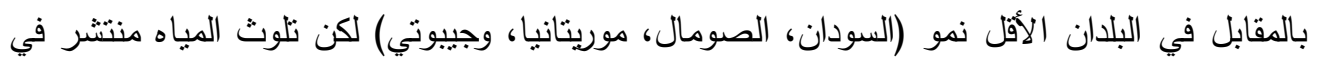
غالبية المدن العربية بينما يزداد ثلوث الهواء مع نزايد أعداد السكان وقد تبين بأن الفضلات الصلبة

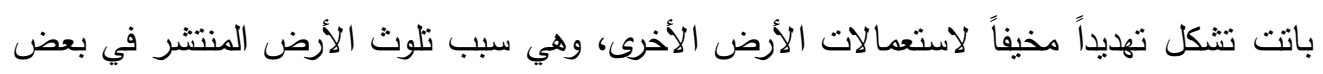

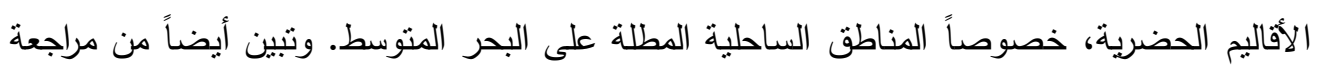
البرامج والأنشطة التي تعتمدها البلدان في الأردن، سوريا، البجرين، نونس، السودان الصومال والعراق وقطر والكويت ومصر والسعودية أنه يوجد تحسن في بعض الأنشطة لكنه لم يحدث تقدم فعال في صناعة المعايير والمقاييس وتذبير التخلص من الفضلات الخطرة. وأن زيادة أعداد السكان في عدد من الضواحي الفقيرة وأحياء البؤس حول المدن الكبرى، ظهرت علامات التلوث وارتفاع نسبة ثاني أوكسيد الكربون التي تغطي أجواء بعض المدن العربية (بيروت، والقاهرة، ودمثق وبغداد، والكويت والدار البيضاء) أما تلوث المياه في مدينة بغداد فهو ناجم عن أن معظم المنشآت الصناعية والتي لئي تشمل شركات النسيج، والألبان، ومعامل البيرة والجلود الواقعة على مجاري الأنهار تصرف فضلاه فلاتها السائلة والصلبة إليها دون معالجة، كما يحصل بالنسبة لمباه نهر دجلة ولهذا التلوث اثره الكبير على تجهيز مدينة بغداد بالمياه. كم أنه يعرقل نوفير مياه الشرب لتلبية الحاجات المنزايدة في الأحياء السكنية. وييرز تأثير بيئة المدينة على الإنسان في مجالات أخرى، فإلى جانب تلوث الميزه المياه والهواء والتربة، يمكن إضافة التلوث الناجم عن الضجيج حيث تنشأ أماكن السكن العشوائي قرب مناطق المطارات وبمحاذاة الخطوط المعدة لهبوط وإقلاع الطائرات (كما هي الحال في حي الأوزاعي والرحل 
العدد الحادي والأربعون

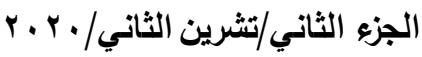

العالي قرب مطار بيروت الدولي) وكذلك حي المطار (r) قرب القاهرة والجزائر والدار البيضاء وهناك نوع آخر من التلوث وهو التلوث البصري لقسم من المدن العربية مما يشوه النظرة البصرية بالعين المجردة لوجود تشوهات من خلال المقارنة في المدن الأفسام والبيانات الموجودة في المدينة والتي

$$
\text { تسبب التلوث البصري. }
$$

ع - مشكلة النقل والمرور

يعتبر النقل بوسائله المختلفة الشرايين والأوردة التي تتطلق من قلب المدينة لأحيائها السكنية داخل المدينة، وبين ضواحيها السكنية على حدودها الخارجية ولولا هذا العنصر الحيوي، لما استطاعت المدينة العصرية أن تتمو وتتطور وتتوسع على رقعة أرضه تمثل أضعاف المرات عما كانت عليه المدينة ما قبل الميلاد وما قبل صناعة الالة التجارية والألة ذات الاحتراق الداخلي. وقد أدى التحضر السريع في المدن العربية إلى تضخم سكان المدن مما يؤدي إلى زيادة مستمرة في

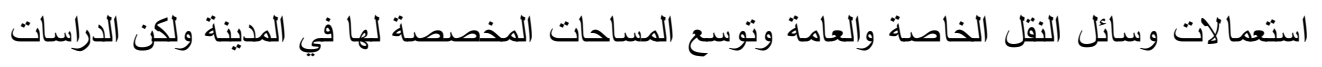
توضح بأن هذه الزيادة هي دون المستوى المطلوب وذلك نتيجة أزمة النقل التي تتفاقم في غالبية هذه المدن من ازدحام حركة المرور وحالات الاختناق في أوقات العمل والحركة الخاصة في المناطق التجارية والصناعية ومن المدن العربية التي تعاني من مشكلة النقل والمرور مدينة عمان بسبب زيادة أعداد السكان مقرونة بزيادة في أعداد السيارات بل ونزداد المشكلة تعقيداً الأمر الذي دفع صانعي

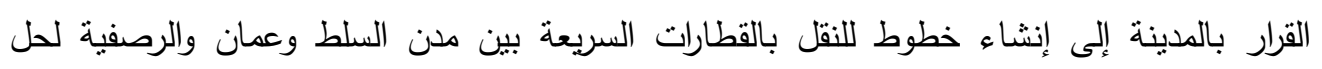

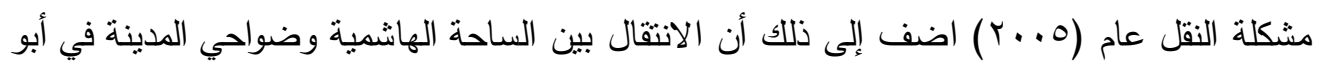
نصير والبقعة ومربع الحمام وناعور يستغرق ما بين .ب - . . دقيقة. وهناك مدن أخرى مثل مدينة القاهرة التي تعكس أزمة النقل بشدة خاصةً في أوقات الذروة من خلال التتقل بين مكان العمل بئل والمسكن، وهذا ينعكس سلباً على نفسه وقدرة المواطن في العطاء والإنتاج وذلك ببذل جهد اقل وإنتاج هزيل كما ارتبطت حوادث المرور بالسيارات السريعة إذ قدر عدد الوفيات في عمان لوحدها عام

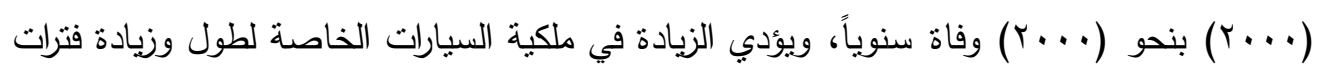
الذروة في حركة المرور وزيادة في الاختناقات بالطرق. وقد أدى ارتقاع عدد السيارات في المدن العربية بدرجة مذهلة إلى ظهور مشكلة النقص في

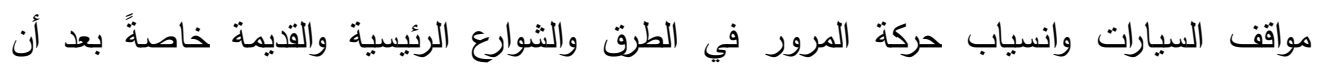
استخدم جوانب الطرق والأرصفة وممرات المشاة والأرصفة وممرات المشاة لوقوف السيارات بالمستوى الذي أصبحت فيه هذه السيارات ووسائل النقل الأخرى تزاحم السكان انفسهم حتى أن 
العدد الحادي والأربعون

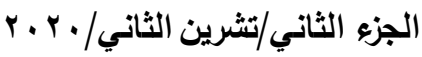

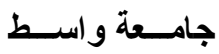

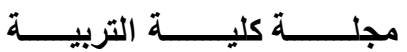

البعض بعتقد بأن المن بنيث من اجل السيارات وليس بهدف الاستقرار الإنساني ثم هناك أيضاً المشاكل الناجمة عن المرور منل الضجيج وتلوث الهواء بسبب عوادم السيارات ثم هناك عنصر

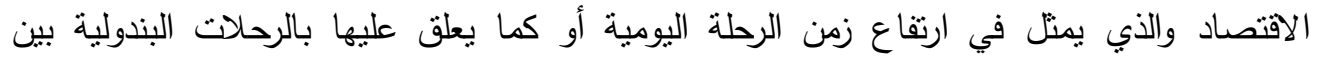

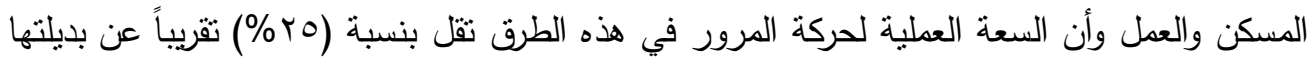
في البدان المتقمة ويرجع السبب الرئيسي في هذا إلى ارتفاع نسبة الطرق غير المعهدة وليس إلى لى لئ الكثافة السكانية الزائدة عن الحد كما يشاع.

\section{The social Problems المشاكل الاجتماعية}

مع تزايد عدد سكان المدينة الحديثة ازداد الطلب على الخمات الاجتماعية من تعليمية وصحية واجتماعية ورياضية، الأمر الذي اقتضى التوسع في إنشاء المدارس بمراحلها المختلفة بالإضافة إلى لى لفائه المعاهد العلمية النقنية والكليات الجامعية، حتى تمكن الطالب من اخذ نصييه في التعليم الاكاديمي والمهني والتقني. هذا بالإضافة إلى إنثاء المستشفيات بمستوياتها المختلفة وتوفير الكوادر الطبية والدوائية للتصدي لأمراض المدينة وانعكاس سلباً على الإنتاج المحلي والوطني. كذلك إنشاء مراكز

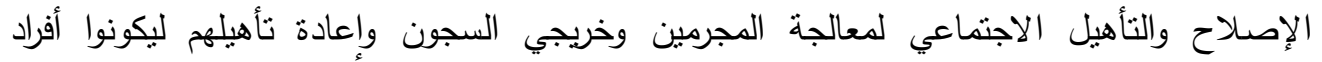

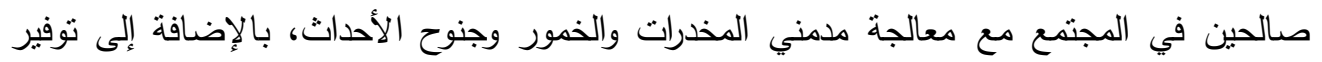

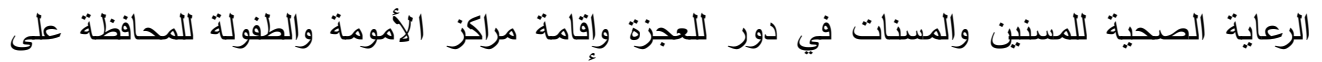

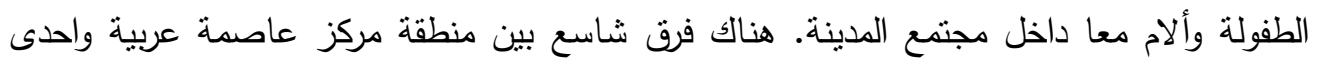

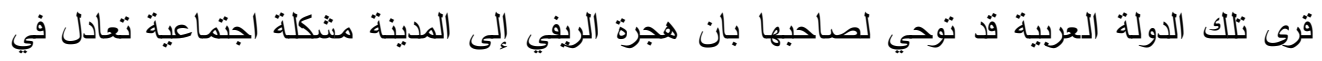

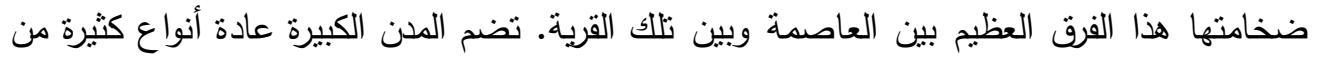

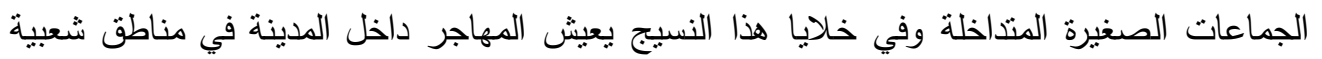
خاصة لأنها تقلل في الفجوة التي تقصل بين موطنه الأصلي وموطنه الجديد. فالمدينة نموذج واحد من نماذج التغيرات السريعة التي قد تحلث في في الثقافة والتي تنترك أثارا بعيدة المدى في البناء الاجتماعي والتي نظهر بجلاء في المشاكل الاجتماعية والثخصية. ولا بد أن تؤكد

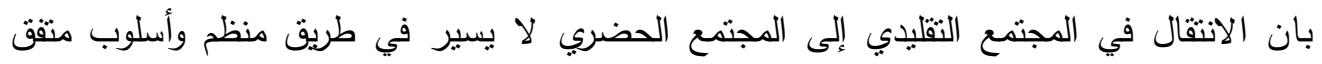

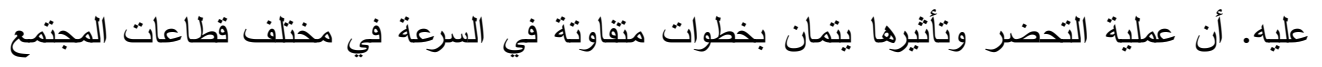

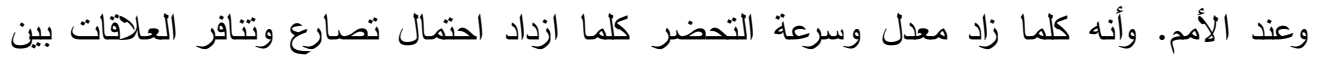

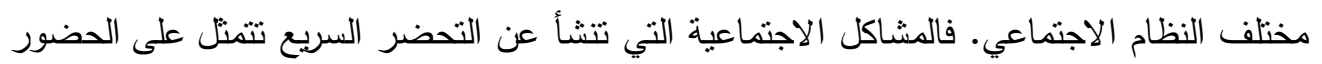

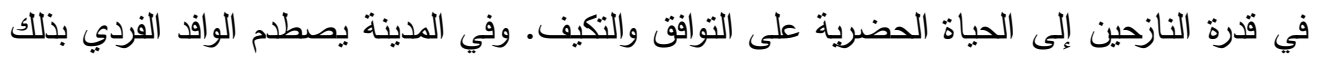


العدد الحادي والأربعون

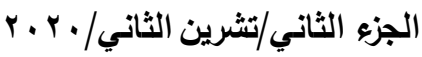

الاتساع واللاتجانس المميزين وغير المفهومين في نظره. وفي البداية يعيش مع أقاربه ثم يحاول أن يتواعم تدريجيا مع الحياة في المدينة. وأن تجمع المدينة المعقد اجتماعياً والمفكك من حيث العلاقات العائلية وصلة القرابة والأشكال الجديدة للترفيه والتسلية وازدياد السكان في المدينة يسبب الضغط المتزايد على الخدات الرئيسية وعلى المرافق الصحية وازدحام حركة المرور والضوضاء والكهرباء والسكن واختلاف المستوى المعاثي بين الريف والمدينة وهناك ظاهرة اجتماعية أخرى متولدة عن الهجرة وتعيشها بعض المدن الغربية فمثلاً بغداد تعيش ظاهرة التكتل السكاني سواء كان تكتلاً يليق

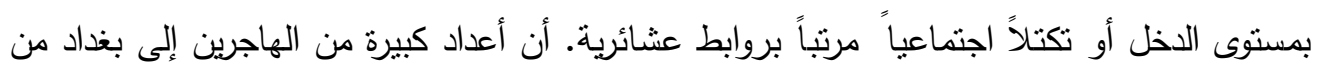

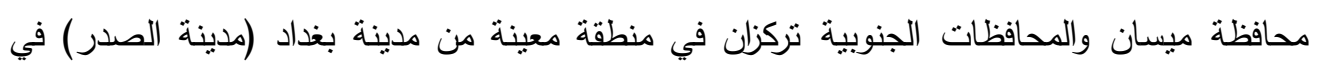

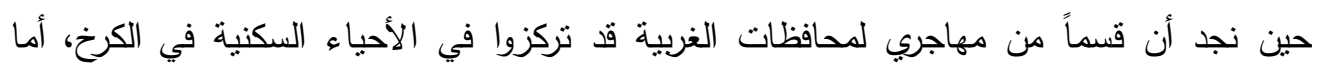
مهاجري المحافظات الثمالية فقد تزكزوا في مناطق باب الشيخ وشارع الكفاح وفي منطقة الخليج العربي هناك ظاهرة اجتماعية مميزة نتيجة الهجرة المتصاعدة من جنسيات متعددة مما أدى إلى إغراق منطقة الخليج العربي بالعناصر الأجنبية الوافدة بشكل لا مثيل له في العالم. يعمل على تحويل

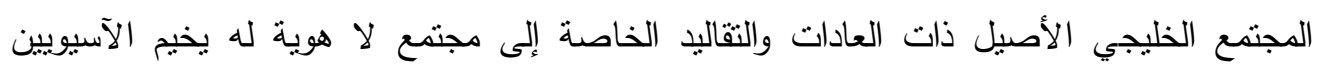
والافارقة والأوربيين وغيرهم. وهؤلاء اثروا بالبيئة الاجتماعية للخليج العربي ونقلوا إلى مجتمعه جميع سلبياتهم. فعلى سبيل المثال نجد في الثركات الكبرى أثرت ثناتي جنسية (مثل منطقة الشعبية الصناعية في الكويت) يعملون تع ساعات العمل ويتفاعلون مع بعضهم وبعد إنهاء الدوام يتجه العاملون إلى جماعاتهم وعلاقاتهم مع أبناء جنسهم ووطنهم. وبعبارة أخرى فأن المجتمع من الناحية السوسيولوجية يتكون من عدة ثقافات وجنسيات ونتيجة

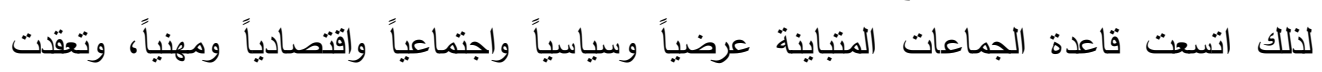
العلاقات الاجنماعية وبرز بالتالي مشكلات أثرت على المدينة واستقراراها وعلى سبيل المثنال لا تشير بعض الإحصائيات الرسمية حول مسائل الأمن والعدل في دولة الإمارات العربية المتحدة أن مجموع

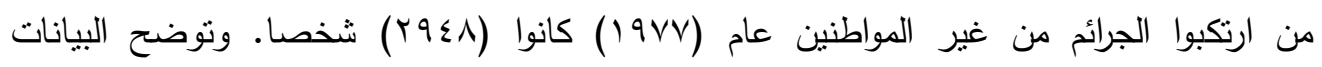

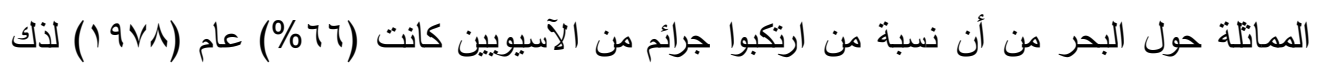
فان مشكلة العمالة الوافدة هي مجرد جزء كل مشكلات هذه المجتمعات وعلاقاتها بأفرادها وهناك مشكلة. اجتماعية ظهرت في منطقة الخليج وهي انتشار القيم الاستهلاكية في الأسرة مما أو باستمرار بأزمات مالية قاسية قد تذفع بعضا من أعضاءها للسير بطرق غير مشروعة للحصول على المال، 
العدد الحادي والأربعون

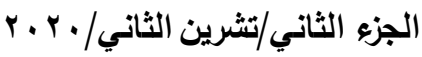

حيث معظم الأموال التي كان من المقرر أن تتجه نحو الاستثمار والإنتاج والتتمية تحولت إلى قطاع الخدمات والاستيراد لمواد استهلاكية.

يضاف إلى ذللك أن المهاجر من الريف إلى المدينة يسكن في الأحياء الفقيرة والبائسة ويصاب بأمراض نفسية وانفصام الثخصية وعدم القدرة على اتخاذ القرار الصائب ثم يعملون بقطاع الخدمات الهامشية يشكلون يسمى جيش البطالة الاحتياط في المدن ونظير أيضا الأغلال الشخصي والأغلال الاجتماعي، كذلك أن الجرعة والسرقة والبغاء والأمراض العقلية وإدمان الخمور والمخدرات تظهر في عائلات هؤلاء المهاجرين إلى المدينة أن هذا النوع من مشاكل التحضر يعتبر من اخطر واهم المشاكل التي تعاني منها المدينة العربية إذ أنه يحط من نوعية حياة الإنسان في المدينة الذي أنشئت وطورت المدينة من أجله وهو خلق بيئة صغيرة وأمينة وصالحة لمعيشة الإنسان وأخيرا فان المدينة الحديثة في حاجة ماسة لخدمات اجتماعية فاعلة وكفؤة تودي خدماتها لسكان المدينة بكل كفاءة وأن عجز عن ذلك في كلها أو بعضها فسوف توقع المدينة المزيد من الإجرام وجنوح الأحداث وانتشار الأمراض وتلوث البيئة مادياً ومعنوياً وبالتالي تشكل النسيج الحضري للمجتمع فيه.

\section{צroblem of weak urban planning devices -مشكلة ضعف أجهزة التخطيط العمراني}

إن مشكلة ضعف أجهزة التخطيط العمراني المتمنل في افتقاره الكوادر التخطيطية من مختلف التخصصات في الدوائر البلدية للمدن العربية أدى إلى أنه لا يوجد في بلديات قسم من المدن العربية مخططين وتظهر الحاجة إلى درامات علمية للنقاط الرئيسية للطرق بمختلف أنواعها على أسس استيعابها لحركة المرور الحالية والمتوقعة. وأن عدم وجود سياسة واضحة للتحضر في الدول العربية لا يعطي صورة واضحة لوضع المدن في الاطار السليم وبالتالي تتم جميع التوقعات على اجتهادات المخططين. وأن عملية إعداد التصاميم الأساسية للمدن لا تتم ضمن اطار التأثير الإقليمي الذي يحدد وضع المدن والتجمعات البشرية والدور الذي خصص لكل منها بما يضمن نمو وتطور المدن داخلياً صمن مخطط واضح كما أن عدم وجود أجهزة تؤهله ذات صلاحيات واسعة وإمكانيات مالية وفنية كبيرة يعوق عملية برامج التخطيط العمراني. لللك حصل النقص في الخدات وزيادة ظاهرة السكن العشوائي على اطراف مداخل المدن وكذللك التجاوزات المستمرة في تغيير استعمالات الأرض من سكن إلى تجارة أو صناعة أو بالعكس نظراً لضعف جهاز الرقابة الإدارية اليومية على قيام وتشييد المباني في المدن العربية. والتخطيط العمراني في الدول العربية لا يجد المناخ الطبيعي والعوامل المساعدة لتسهيل عمله وذلك لعدم إشراك المواطنين 
العدد الحادي والأربعون

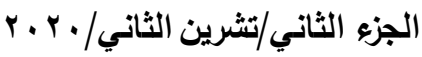

والاتحادات والمنظمات الشعبية ووسائل الإعلام من إذاعة وتلفزيون وغيرها في عمليات التخطيط

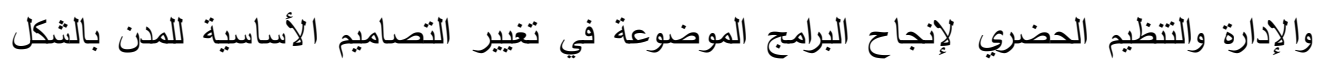
الأي يعكس إيجابياً على المواطنين في تلك المدن. وهناك مشكلة أخرى تعاني منها يعض الدول العربية هو انفصال عمليات التخطيط العمرانية من أجهزة مستقلة عن عمليات التخطيط الاقتصادي الاجتماعي قد تسبب في تفكلك العمليات التخطيطية الشاملة رغم إيجاد مجموعة من خبراء الأمم المتحدة في دراستها عن تكامل التخطبط العمراني بالتخطيط الاقتصادي الاجتماعي عام (س (91 ). أن قلة المتخصصين في مجال التخطبط العمراني أدى في كثير من الدول العربية إلى إرسالهم إلى الدول الأوربية من اجل التدريب واكتساب الخبرة والتخصص في عمل التخطيط الحضري. ومن كل ذلك نرى أن المدن الكبيرة في الدول العربية تقدمت وتطورت في غياب التخطيط العلمي الذي يناوله الاقتصاد والاجتماع وحتى الطبية، وهذا أدى إلى زيادة مشكلات المدن الكبرى وتعقيد هذه المجتمعات التي تحتاج إلى خدمات متميزة وعنصر بشري متخصص يقوم على إدائها بموجب تخطيط علمي سليم ينبع من واقعها وطبيعة تكوينها وظروفها ومقوماتها وأهدافها الحضارية.

V - Vشكلة تقليص وتأكل الأرض الزراعية

\section{The Problem of reducing and scarcity of Agricultural Land}

أن التحضر السريع برز في المنطقة العربية أدى إلى التوسع الكبير في مساحات المدن لاستيعاب تلك الأعداد الكبيرة المهاجرة من الريف إلى المدن وبما أن معظم المدن العربية تقع في أقاليم زراعية خصبة تعتمد عليها المدن باعتبارها مورد هاماً لغذائها وإمدادها بالخضراوات والفواكه. فان التوسع الحضري بما فيه التوسع الحضري العشوائي يزحفان كزحف الرمال مما يؤدي إلى تقليص

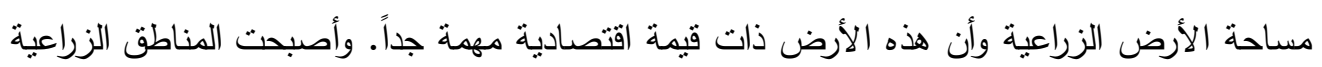
تتتاقص مساحتها بتزايد مساحة المراكز العمرانية الواقعة في وسطها وهذه تعد مشكلة حيث تقلصت مساحة الأراضي الزراعية وتوسعت المناطق الحضرية وسبب حدوث نقص في الإنتاج الزراعي ومنتوجاته المتتوعة بسبب تقليص مساحة الأرض الزراعية وهكذا تحولت تلك المناطق الزراعية إلى الى مساكن ومزارع الدواجن وتجريف الأرض الزراعية. لذلك فان ملاك الأراضي المجاورة يحاولون بشتى الطرق لاستثمار مشكلة الإسكان وإفراز هذه ودأ الأراضي كقطع سكنية لبناء دور عليها دون موافقة الدولة أو باستخدام أساليب غير شرعية لإخفاء الثرعية على هذه الأعمال ولكون معظم التجمعات السكنية تقع وسط الأراضي الزراعية فقد ساعد 
العدد الحادي والأربعون

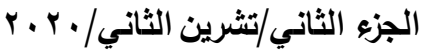

الضغط الثعبي الذي تولده أزمة الإسكان على تراخي الدولة في مصادرة الاعتداء على الأرض ووقف التضخم العشوائي للمدن والقرى على حساب الأراضي الزراعية. وعلى سبيل المثال وصلت هذه المشكلة في مصر إلى أوضاع خطيرة في السنوات الأخيرة حيث

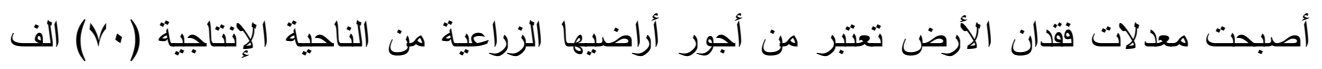

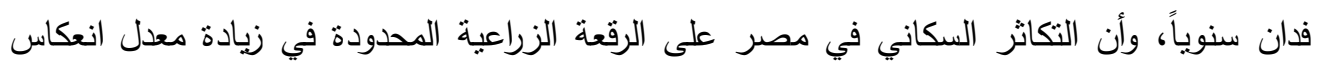
الرقعة الزراعية لدرجة أن العلماء قدروا أنه على أن تخسر مصر خلال السنوات العثر القادمة (في

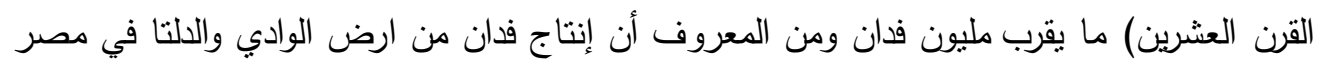
يعادل عدة أضعاف متلكه من الأرض المستصلحة. وأن اعتماد التوسع الأفقي للعديد من المدن العربية

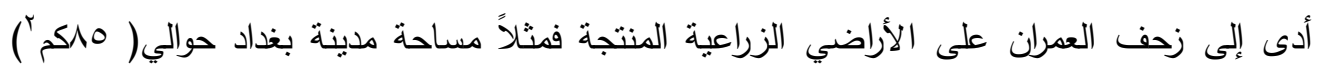

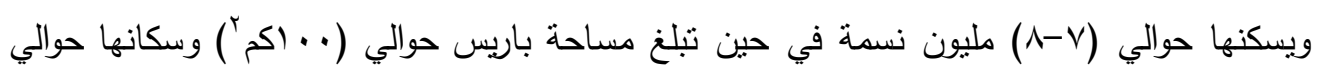
ثمانية ملايين نسمة.

ثانياً: سبل وطرق معالجة مشاكل المدن العربية Ways and methods to address the Problems of Arab cities

Housing Problem - مشكلة السكن بالمدينة لمعالجة هذه المشكلة الكبيرة في المدينة العربية لا بـ من اتخاذ الإجراعات التالية: ا - لذلك على كل دولة عربية أن نتأخذ إجراءات استراتيجية عامة لحل مشكلة السكن عن طريق مشاركة الدولة من خلال الجمعيات الإسكانية أو تشجيع القطاع الخارجي من اجل زيادة

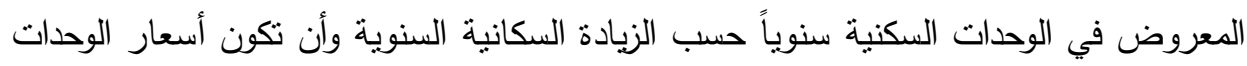
السكنية مناسبة حسب دخول السكان وخاصة الطبقات الفقيرة. r - اختيار النماذج السكنية ذات الكلفة القليلة وتتسجم مع حضارة وثقافة الشعوب العربية من حيث البيئة المناخية والصحية. r - إصدار قوانين حديثة لمتابعة كيفية توزيع الأراضي على السكان وبأسعار مناسبة من اجل بناء الوحدات السكنية، وكذللك تمديد الإيجارات بحيث تكون منوازنة مع دخول المواطنين. ـ - التشجيع على إعطاء قروض الإسكان لذوي الدخل المحدود وبفوائد ملكية. 0- إنشاء الجمعيات التعاونية الإسكانية لبناء الوحدات السكنية للمواطنين وعدم فرض الرسوم والضرائب عليها. 
العدد الحادي والأربعون

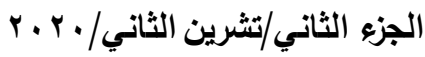

ب - القيام ببناء مجمعات سكنية في اطراف المدينة مزودة بكافة الخدمات الرئيسية وبالتقسيط المريح مع دفع مبلغ مناسب كمقدة لتلك الشركات الإسكانية.

V - مساعدة وتشجيع بناء المساكن الشعبية للطبقات الفقيرة وصيانة المباني القديمة. ^ - المحافظة على بيئة المدينة القديمة المندهورة والحفاظ على تراثها وأصالتها ومساعدة أصحابها للبقاء فيها بعد ترميمها بصورة تخدم المدينة القديمة. 9 -توفير جميع المواد الإنشائية والسمنت من خلاء إنشاء صناعات مواد البناء محلياً وأن تكون أسعارها مناسبة بشكل عادل. • 1-إنشاء طرق نقل جيدة لنقل المواد الإنشائية وبأسعار مناسبة وكذلك لنقل السكان إلى تلك المناطق الجديدة. ال-نشجيع السكان على السكن في العمارات السكنية من خلال البناء العمودي التي لا يحتاج إلى مساحة ارض كبيرة. ז ب - عدم الموافقة على تحويل جنس الملك للأراضي الزراعية إلى جنس للسكن للمحافظة على الأراضي الزراعية وزيادة إنتاجها.

\section{Problem Preserving of old Arab cityة r بككة المحافظة على المدينة العربية القديمة} من صفات المدن العربية القديمة أنها تؤمن علاقة مزدوجة مكانية وزمانية بين الإنسان ومحيطه وهذا هو سر بقاء المدينة واستمرارها. لذلك فالمدن نتطور وتزدهر من خلال زيادة التتاسق بين

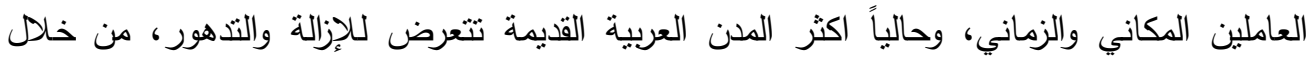
إزالة معظم معالمها الحضارة والأصالة العربية للمدن القديمة، لذلك يجب المحافظة وحماية المراكز والأبنية التجارية والتاريخية لتلك المدن في خلال سن قوانين وتشريعات قانونية تؤكد للحفاظ على ولى المدينة القديمة وتراثها الأصيل وتلك المناطق تغير من خله النشاط الثقافي والإرث الحضاري للمدينة العربية ونبقى هامة كبيرة على مدى الزمان من خلال الأجيال المتعاقبة وتصبح تلك المناطق

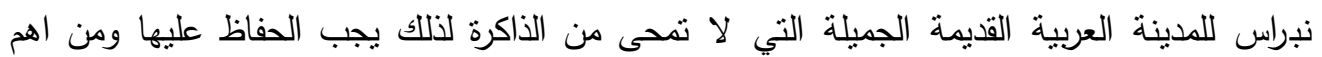
الإجراءات ذات الصفة القانونية هو الحفاظ على بيئة تلك المدن وعدم الموافقة على تغير تصميمها وعدم إزالة أي جزء من معالمها المعمارية التراثية وعدم تحويلها إلى أراضي لتجارة العقارات والوحدات السكنية لكي تبقى في ذاكرة الإنسان مهما طال الزمن وأن واضع المدن العربية القديمة حالياً يمكن وصفه بان هناك مدن تحاول الحفاظ على جسدها وارثها الثقافي وهناك مدن أصبحت في خبر كان 
العدد الحادي والأربعون

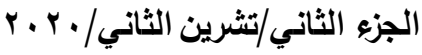

وفقدت صفاتها ولم تبق في الذاكرة وهناك مدن قديمة في طريقها للزوال إذا لم يوجد من يحافظ عليها من قبل الأجهزة الحكومية والثقافية ذات العلاقة بموضوع تراث المدينة العربية القديمة والمحافظة عليها من الزوال.

Environment of the city and Pollution Problems بيئة المدينة ومشاكل التلوث وسوف نحدد بعض الوسائل من اجل المحافظة على بيئة المدينة العربية: ا - منع جريان المجاري السكنية المنزلية الصناعية وصبها في الأنهار لان ذلك يسبب تلوث المياه وتسبب مشاكل صحية كبيرة للسكان. ץ-إصدار قوانين بعدم الموافقة على إنشاء الصناعات بالقرب من المن وإنما تخصيص أماكن خاصة بها في الأفسام الجنوبية من المدينة لأنها تنفث الدخان والأتربة وتؤثز على صحة ساكني المنطقة السكنية. r-تكليف الدوائر البلدية في كل مدينة بوضع ضوابط المحافظة على بيئة المدينة من خلال إجراءات فرض الغرامات على المخالفين من اجل نوفير النظافة وجمع النفايات في أماكنها الخاصة المخصصة

ع -إنشاء مراكز للحجر الصحي للتخلص من كافة الفضلات خارج المدينة وبناء مجاري للصرف الصحي بالشروط الصحية المعمولة لكل مدينة. ه- الحفاظ على توزيع مياه الشرب من خلال مشروع إسالة الماء ووضع الكلور فيها وتعقيمها باستمرار حفاظاً على الصحة العامة. ج -ومن اجل الحفاظ على بيئة المدينة لا بد من تشجير شوارع المدينة وتوفير مواقف وباركات وحدائق عامة للاستفادة منها من قبل سكان المدينة للنزهة. V- إصدار قوانين صارمة بحق من يقوم بقطع الأشجار من البساتين الواقعة حول المدينة وزيادة مساحتها والمحافظة على الغابات. 1-بناء الأحزمة الخضراء حول المدن Green belts للمحافظة على بيئة المدينة وجماليتها ومكافحتها للتصحر . و - لأهمية البيئة وفوائدها من الواجب إخخالها كمادة علمية دراسية في مختلف المراحل الدراسية لبيان أهمية البيئة والمحافظة عليها. 
العدد الحادي والأربعون

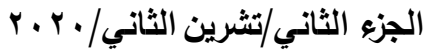

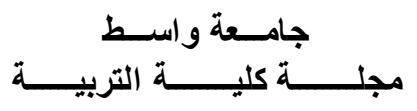

ع -مشكلة النقل والمرور Traffic Problem

ا -من اجل تخفيف الازدحام داخل المدن يجب الالتزام بالقواعد والإرشادات المرورية واحالة المخالف لافع غرامة مالبة حتى لا تتكرر الأخطاء لاق

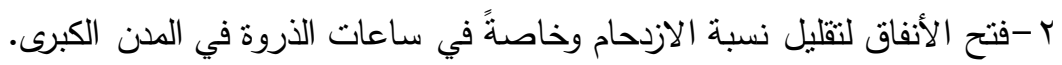
r-نظراً لكثرة السيارات وأعدادها سنوياً لابد من بناء الباركات في مختلف مناطق المدينة وخاصةً في المدن الكبرى عن طريق الباركات في العمارات العالية إضافة إلى الكراجات الموجودة داخل المدينة للسيارات عند الأحياء السكنية وعند مداخل الدوائر الحكومية

$$
\begin{aligned}
& \text { بسبب الزخم الكبير وبناء } \\
& \text { والمؤسسات الأخرى. }
\end{aligned}
$$

ع -إقامة انفاق للسابلة عند تقاطع حركة السابلة مع الثوارع الرئيسية وخاصة في التقاطعات والساحات. ه -من المحبذ دراسة التصميم الأساسي لكل مدينة ودراسة شبكة المواصلات فيها بحيث تتلائم مع الواقع القائم للمدينة دون أن تسبب مشاكل مرورية. 1 -بناء الطرق السريعة في مجال المدينة والتي نكون فيها الحركة مستمرة وغير منقطعة.

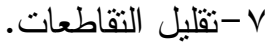
1-نطبيق نظام Traffic light الإشارات المرورية لأنه طريقة حضارية تساعد على نقليل الحوادث المرورية واحترام الإرشادات المرورية. 9-وضع كاميرات مراقبة على الثوارع الرئيسية لمتابعة ومراقبة أصحاب السيارات الذين لا يلتزمون بالإشارات الضوئية والسرعة المحدة.

\section{Addressing Social Problems in the Arab city}

\section{هـ-معالجة المشاكل الاجتماعية في المدينة العربية} المدينة رغم تخصصها بالنشاطات التجارية والمالية والإدارية، ليست إلا بيتاً ومكاناً للعلاقات الاجتماعية والتلاقي الاجتماعي وهي بدون وجود الإنسان فيها تبدو مفقرة خالية كالصحراء.

ا -بسبب زيادة سكان المدن يزداد الطلب على الخدمات الاجتماعية المتتوعة ومن ضمنها الخدمات التعليمية والصحية والرياضية والاجتماعية. 
العدد الحادي والأربعون

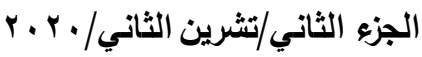

r-التوسع في بناء المدارس بجميع مراحلها الدراسية اعتباراً من روضة الأطفال والمدارس الابتدائية والمتوسطة والإعدادية، إلى بناء الجامعات والمعاهد العلمية حتى ينمكن كل طالب علم من اخذ دورة في التعليم الاكاديمي والمهني والتقني. r -بناء المستثفيات والمراكز الصحية وتهيأة الكوادر الصحية والطبية المختلفة لأمراض المدينة ومعالجة السكان من خلا توفير الكوادر الكفؤة وأن هذه المؤسسات الصحية لا تقل أهمية عن توفي الماء والغذاء وطرق النقل وجميع الخدمات العامة الأخرى في المدن الحديثة في البلدان العربية. ع -بناء مراكز لتأهيل السكان المصابين بالأمراض النفسية والعقلية وتهيأة الظروف الجيدة لهم ومعالجتهم بأسلوب إنساني لانهم كسائر أبناء البشر الأخرى.

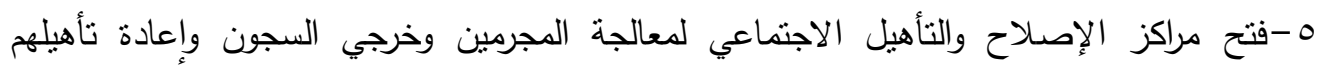
ليكونوا مواطنين صالحين في المجتمع، بالإضافة إلى معالجة مدمني المخدرات والخمور وجنوح الأحداث.

7 -بناء دور العجزة لكبار السن من الجنسين الذين ليس لهم من يهنم بهم أو يرعاهم. V-ومن اجل المحافظة على الطفولة والأمومة معاً داخل المجنمع المدني لذلك يجب الاهتمام بالطفل والأم معاً من خلال وجود مراكز الأمومة والطفولة في المدينة. 1 - إصدار قوانين تشجع على حماية ووحدة الأسرة كنواة رئيسة في المجتمع المدني والمحافظة عليها من اجل كيان عائلي متماسك ومعالجة العنف الأسري. 9-وجود الضمان الصحي والاجتماعي لكل فرد في المجتمع بالمساواة وبدون تمييز . • 1-التأكيد على إيصال الخدمات الاجتماعية وخاصةً في الأحياء الفقيرة من الخدمات الصحية والكهرباء والماء والمجاري لتحقيق العدالة الاجتماعية. Iا - التشجيع على بناء ومناطق للترويج والترفيه الاجتماعي منل الحدائق العامة والسارح والسينما وملاعب الأطفال وأن يكون التوزيع حسب أعداد السكان في المناطق السكنية في المدينة. r إصدار قوانين وتشريعات للحفاظ على إحلال الغير ومكافحة الجرائم وبث روح الأمن وعدم التعدي على حقوق الآخرين. با-نظراً لأهمية المشاكل الاجنماعية في المدينة لللك من الضروري اعتبارها مواد أساسية في

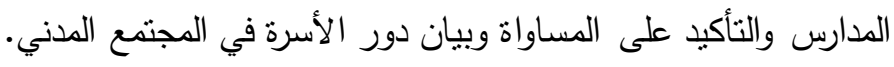


العدد الحادي والأربعون

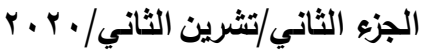

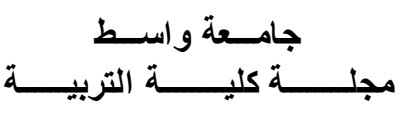

\section{Address the Problem of urban Planning devices}

1 - الاهتمام بالتخطيط العمراني لما يمتله من أهمية كبيرة لبناء المدينة وتركيبها الداخلي. ץ-وضع استراتيجية معدة من قبل الأجهزة التخطيطية المتخصصة في تخطيط المدن بأسلوب علمي وعقلاني في مدروس للمحافظة على مورفولوجية المدينة وتوسعها المستقبلي. r - على جميع المخططين أن يضعوا نصب أعينهم عند وضع مخططات المدينة الربط والعلاقة بين مدين الماضي من حيث التراث والتاريخ والحاضر لمراعاة معالجة مشاكل كثيرة مثل أزمة السكن وطرق النقل بأنواعها. ع - المطلوب في التخطيط العمراني هو اعتماد خطة متكافئة وشاملة تأخذ بعين الاعتبار وتعتبر المدينة الكبرى فيها مراكز نواة مع بيان آفاق توسعها وأهمية دراسة استعمالات الأرض داخل المدن.

ه-يجب تحديد الغاية والأهية في أية عملية للتخطبط حتى يصبح التخطيط الحضري ناجحاً وبيان الأهداف الضرورية لعملية التخطيط، على أن تتضمن التوازن الاقتصادي وتخفيف الازدحام في المدن وتحقيق العدالة الاجتماعية. 1 - اهم في التخطيط العمراني هي تلك العمليات والخطط القابلة للتنفيذ والتي تتلاعم مع أوضاع البيئة العربية الطبيعية والحضارية وأن تحقق الشخصية للمدينة. V- التأكيد على استخدامات الأرض داخل المدينة من حيث مراعاة كل استعمال بحيث يحقق التكامل والترابط بين أجزاء المدينة دون بانقطاع أو مشاكل والمحافظة على تراث المدينة من جوانبها المتعددة.

^ - التأكيد على وجود المناطق المفتوحة والمناطق الخضراء لتوازن البيئة الحضرية ولضرورة وجودها لأنها تحقق فوائد بيئية وخلق جو من الراحة النفسية للسكان. 9 - أنشاء الباركات العامة والحدائق للراحة والاستجمام. 
العدد الحادي والأربعون

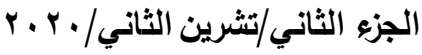

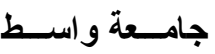

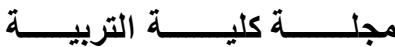

V Vمعالجة مشكلة تقليص وتآكل الأرض الزراعية

Address Problem of reducing and Scarcity of Agricul tural Land

من اجل المحافظة على الأرض الزراعية يجب العمل بما يلي:

In order to Preserve agricul tural Land the Following must be done.

1-المحافظة على الأراضي الزراعية وإصدار القوانين الذي يحرم تحويل تلك الأراضي الزراعية إلى أراضي سكنية.

ץ-تهيأة وتوفير الخدمات الأساسية في كل من الريف والمدينة من اجل الحفاظ على الأرياف وذلك تشجيعاً لزيادة الإنتاج الزراعي بمختلف أنواعه.

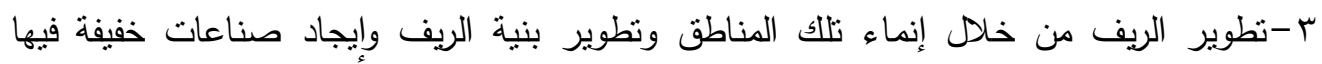
وكنلك تشجيع الحرف والمهن الزراعية في الريف من اجل نوفير مقومات الحياة واستصلاح الأراضي.

ع -وضع قوانين ومعالجات لتخففف الهجرة من الريف إلى المدينة لها لها من أضرار اقتصادية واجتماعية علة الواقع في الريف وخلق الضغط على الخدمات الأساسية في الددن.

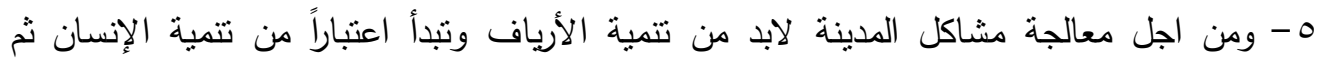

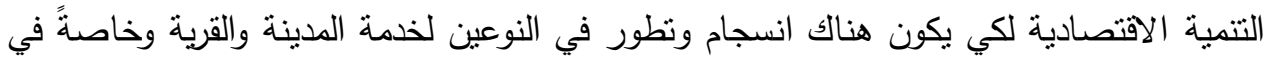

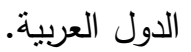
צ-التأكيد على الثورة الزراعية في الأرياف لان تتمية الموارد الزراعية هي موارد تساعد على تطور القطاع الزراعي وتحقيق مستقبل كبير في المنطقة لان الزراعة نفط دائم.

خلاصة البحث الموسوم ((مشاكل المدن العربية وسبل معالجتها))

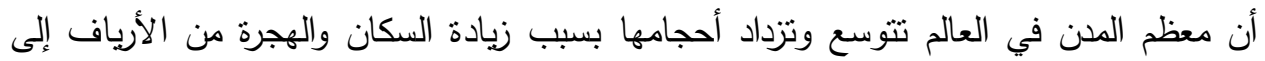
الدنن للبحث عن فرص العمل لان مستوى الأجور اعلى من الأرياف وبشكل خاص في في مدن الداد الدول

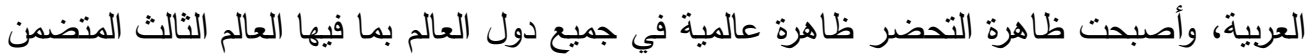
للاول العربية وهي ترتبط بعدة عوامل اقتصادية واجتماعية، ونلاحظ بان التحضر في الدول المنطورة

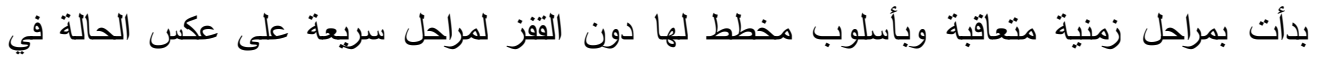
الدول العربية الني بدأت فيها ظاهرة التحضر بأسلوب سريع وغير مخطط وبصورة ونطية عشوائية أثرت على حجم مدن الدول العربية وسببت مشاكل عديدة من خلال زيادة قوافل الوافدين من الأرياف إلى فيلى الددن بحثاً عن ظروف حياة افضل من الأرياف، ولكن عملية التحضر السريعة في الددن العربية 
العدد الحادي والأربعون

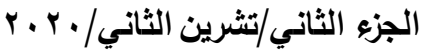

سببت ظهور مشاكل عديدة من الصعوبة السيطرة عليها بشكل شامل بل يمكن إيجاد حلول مرحلية تؤدي إلى التقليل من آثارها داخل المدن العربية وفي منت البحث بنيت مشاكل المدن العربية وسبل معالجتها، ومنها مشاكل السكن والنقل والضغط على المرافق العامة والخدات الرئيسية منل توفير الماء والكهرباء وعمليات الصرف الصحي والمجاري والخدمات التعليمية والصحية والاجتماعية، ومشاكل المدن العربية القديمة، ومشاكل تأكل الأرض الزراعية... الخ، بحيث لا يستطيع الثخص وله الوافد من القرية التأقلم بسرعة مع الواقع الجديد في المدينة إضافة إلى خلق مشاكل نفسية واجتماعية من خلال سكن عدة عوامل في البيت الواحد والحمامات تكون مشتركة وكذللك الحصول على المياه غيرها، وهذه المشاكل تتاولتها بالتقصيل في منن البحث مع بيان معالجة كل مشكلة. وتعاني المدينة العربية مشاكل أخرى منها نقص الخدمات الترفيهية والمناطق المفتوحة والمناطق الخضراء وإضافة إلى حدوث مشاكل اجتماعية متعددة. وأن اكثر المدن العرية توسعت بصورة عشوائية وخاصةً في نهاية القرن العشرين بسبب الهجرة السريعة من الأرياف إلى المناطق الحضرية وهذا سبب نقص كبير في القوى العاملة الزراعية في الأرياف التي تعتبر المصدر الأساسي لتزويد السكان بالغذاء، والضغط على الخدمات الأساسية في المدن بسبب زيادة أعداد سكان المدن العربية مما أثرت على التركيب الداخلي للمدن العربية.

\section{المصادر}

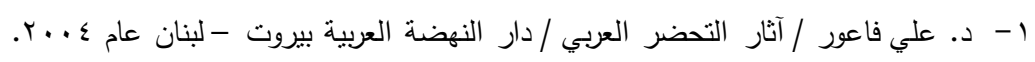

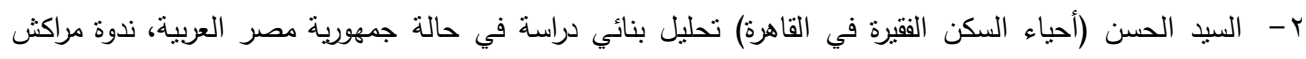

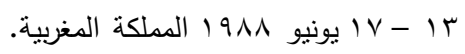

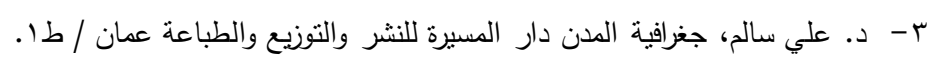

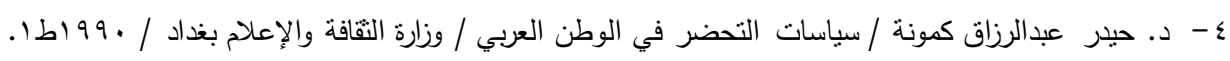

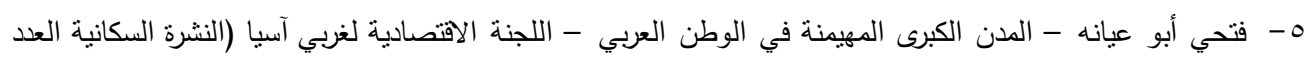
$.191 \cdot-19$ צ- احمد النكلاوي، القاهرة الكبيرة في نفوس مدين القاهرة دراسة في علم الاجتماع الحضري، دار النهضة العربية $.19 V \mathrm{r}$

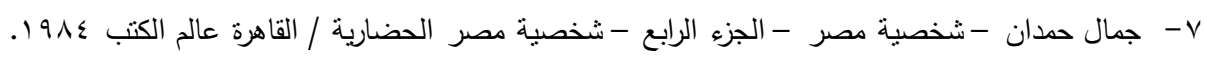

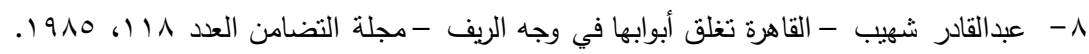

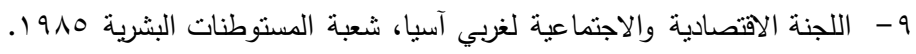
• 1- احصاعيات الجهاز المركزي للإحصاء. 
العدد الحادي والأربعون

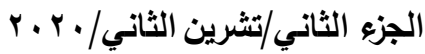

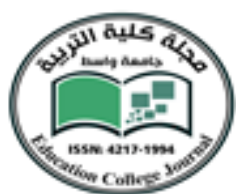

1 1 - علي عمورة الميلودي، معالجة ظاهرة السكن العشوائي في الجماهيرية العربية الليية 1911، مراكث / المغرب.

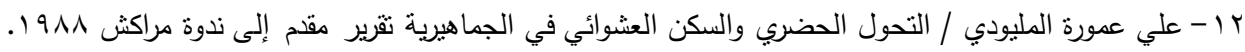

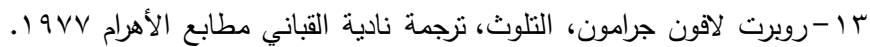

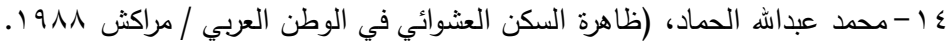

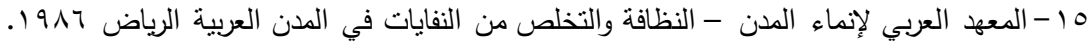

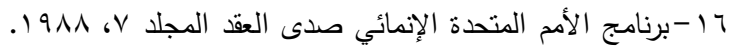
Vا - مشكلة النقل والمرور في المدينة العراقية، معالجات وحلول للاكتور حينر كمونة وزارة الثقافة والإعلام الموسوعة

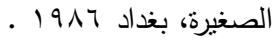

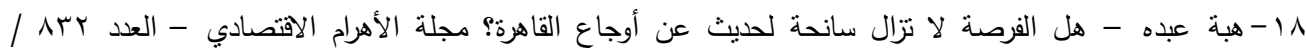
$.19 \wedge \varepsilon$

19-محمد مهدي الزراي ورسول الجابري - الهجرة إلى بغداد 19 199 - 199، أسبابها، آثارها، سبل علاجها وزارة التخطبط هيئة التخطبط الإقليمي. • ץ-د. حيدر كمونة / الممارسات التخطيطية للمدينة العرقية مجلة آفاق عربية العدد • 1 / دار الثؤون الثقافية / وزارة

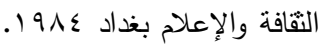
ا اr-د. عبد الباقي محمد إبراهيم - النمو العمراني في الددينة العربية - مجلة البلديات العدد V وزارة الثؤون البلدية

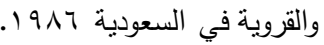

r r-عباس مبروك - الأفمار الصناعية وطائرات الاستطلاع المصرية ترصد كل التعديلات على الرقعة الخضراء -

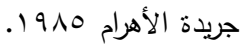

